\title{
Regression analysis to design a solar thermal collector for occasional use
}

\author{
G. Ciulla \\ Dipartimento di Ingegneria \\ Università degli studi di Palermo, viale delle scienze, Edificio 9, Palermo, Italy \\ Correspondent author email: giuseppina.ciulla@unipa.it \\ A. D’Amico ${ }^{1}$, V. Lo Brano ${ }^{1}$, A. Buscemi ${ }^{1}$ \\ ${ }^{1}$ Dipartimento di Ingegneria \\ Università degli studi di Palermo, viale delle scienze, Edificio 9, Palermo, Italy ${ }^{1}$ \\ e-mail: antonio.damico@deim.unipa.it,valerio.lobrano@unipa.it, \\ alessandro.buscemi@unipa.it
}

\begin{abstract}
Optimal design of a solar thermal system is necessary to minimize payback time and to diffuse renewable energy use for Domestic Hot Water production in residential areas. More accurate design is crucial in the case of seasonal or occasional use of the system; indeed, the standard criteria generally applied to a design system for continuous use, can lead to considerable over-sizing. To speed up the design phase and to help the planner in the identification of the best solution without any complex evaluation or long computational time, it would be interesting to have available a simpler method than the standard procedures, but one that is reliable and accurate for the evaluation of the best configuration,, taking into account occasional use, seasonal and monthly domestic hot water demand, orientation and primary flow rate. To this end, the authors investigated a methodology for the identification of some empirical correlations based on the analysis of data coming from a parametric simulation; in this way the identified correlations can indicate, with high reliability, the optimal design knowing only well-known parameters. In detail, the data output was extracted and processed to evaluate the best design configurations under any operative conditions. Determination of the best configuration identifies the operative parameters that maximize the Solar Fraction of the plant and minimize the auxiliary energy. To highlight the reliability of this methodology, in this work, the authors describe a case study of the Sicilian region proposing a set of simple, reliable correlations that allow the determination of the best tilt angle for monthly or seasonal use. Following the same steps the procedure can be replicate in any context and in any conditions.
\end{abstract}

\section{KEYWORDS}

Solar thermal collector; TRNSYS model; parametric analysis; optimum design; empirical correlation.

\section{NOMENCLATURE}

\begin{tabular}{|ll}
\hline $\mathrm{A}_{\text {coll }}$ & collector area $\left[\mathrm{m}^{2}\right]$ \\
$\mathrm{E}_{\text {gain }}$ & energy collected by the collector $[\mathrm{kW}]$ \\
$\mathrm{H}_{\mathrm{bh}}$ & average horizontal solar beam irradiation $\left[\mathrm{kWh} / \mathrm{m}^{2}\right]$ \\
$\mathrm{H}_{\mathrm{h}}$ & average horizontal solar irradiation $\left[\mathrm{kWh} / \mathrm{m}^{2}\right]$ \\
\hline
\end{tabular}

Published version in Sustainable Energy Technologies and Assessments: https://doi.org/10.1016/j.seta.2020.100638 available

https://www.sciencedirect.com/science/article/pii/S2213138819306538 C <2020>. This manuscript version is made available under the CC-BY-NC-ND 4.0 license http://creativecommons.org/licenses/by-nc-nd/4.0/ This paper is accepted for publication in Sustainable Energy Technologies and Assessments (2020). 


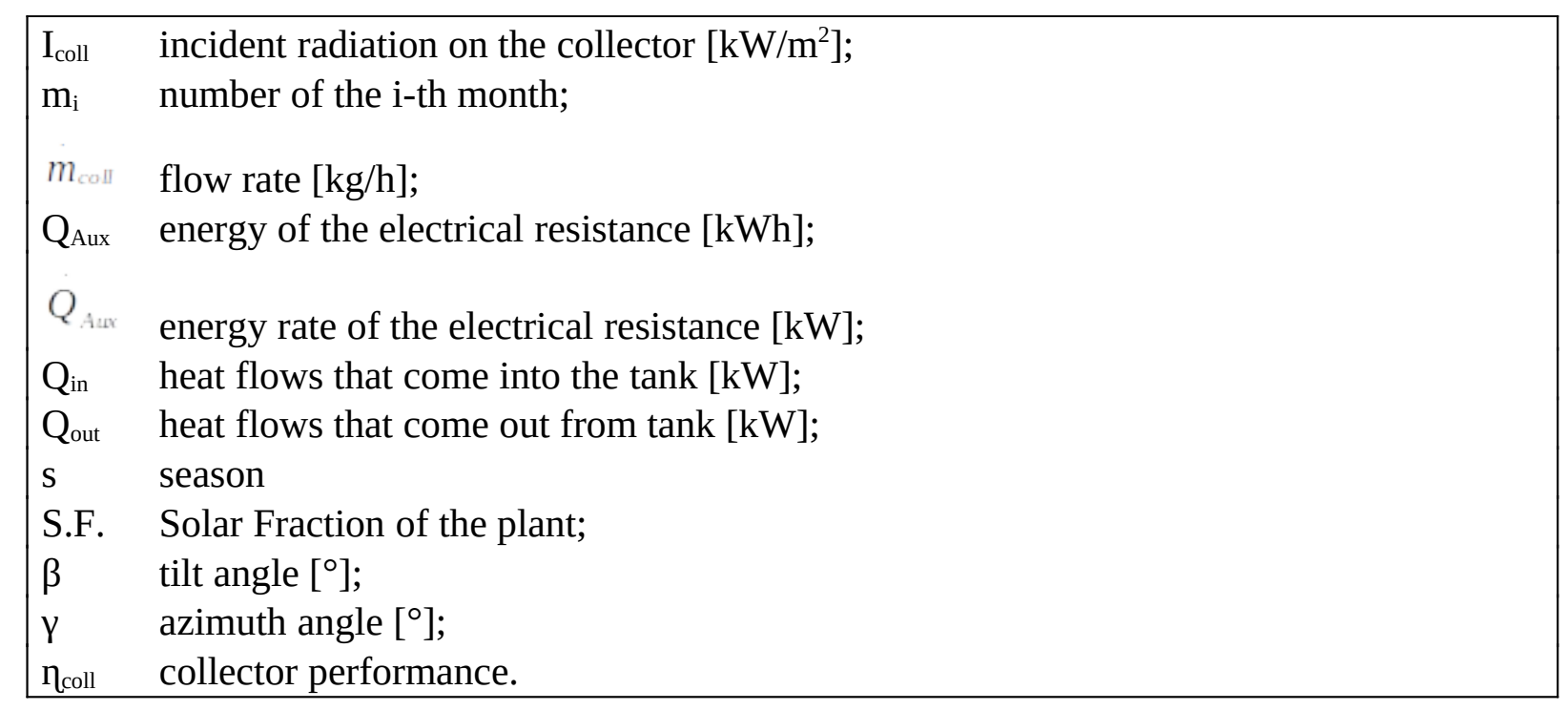

\section{INTRODUCTION}

For the optimum design of photovoltaic or thermal solar systems with any application, it is important to determine performance at the site of installation. The amount of power produced by a solar energy conversion system depends upon the amount of sunlight that is captured [1]. The incident solar energy on a solar system, in various time scales, is a complex function of many factors including the local climate, the azimuth $(\gamma)$ and tilt $(\beta)$ of the collector surface, the ground reflection properties, and so on. In the case of limited area available for exposing the solar collector arrays, as well as in large-scale industrial applications, the evaluation of the exposure, the available insolation, and the site area become of primary importance [2].

The best technological solution to collect maximum daily solar energy is the use of tracking systems; however, sun trackers are often expensive and are not always applicable on a residential scale. Thus, the optimum slopes of solar energy collectors at any latitude, for any surface azimuth angles and for seasonal or monthly use, have to be determined accurately [3]. Solar systems ideally should operate at maximum possible performance and this must be achieved through proper design, construction, installation, and orientation.

The orientation of the collector is described by its $\gamma$ and $\beta$ angles. Generally, systems installed in the northern hemisphere are oriented to the south $\left(\gamma=0^{\circ}\right)$ and tilted at a certain angle [4]. Many investigations have been carried out to determine, or at least estimate, the best $\beta$ angle for such systems. Some of these are, for example, $\beta=\varphi+20^{\circ}[5], \beta=\varphi+\left(10 \rightarrow 30^{\circ}\right)[6] \beta=\varphi+10^{\circ}[7]$ and $\beta=\varphi-10^{\circ}$ [8]. Some researchers suggest two values for the $\beta$ angle, one for summer and the other for winter, such as $\beta=\varphi \pm 20^{\circ}$ [9], $\beta=\varphi \pm 8^{\circ}$ [10] and $\beta=\varphi \pm 5^{\circ}$ [11], where $\varphi$ is the latitude, "+" for winter, and “-” for summer. Some years ago, computer programs were used to calculate the tilt angle which maximizes the amount of yearly solar irradiation received by the collector and the results show that the optimum tilt angle is almost equal to the latitude of the installation site [1215].

Optimum fixed-collector positions based on mathematical models of solar resource are available for places such as Lesotho [13], Egypt [15], Cyprus [16], Brunei Darussalam [17], China [18], Iran [19], the western Himalayas [20], India [21] and Malaysia [22]. Estimation and optimization of the incident solar radiation on fixed tilted surfaces can also be determined using different empirical models [23,24]. A solar radiation data manual for flat-plate and concentrating collectors was made available for the United States of America by the National Renewable Energy Laboratory [25]. The mathematical models of solar resource and measured solar data were used to calculate expected insolation on fixed tilted surfaces at various locations. 
Other works defined the optimum fixed-collector positions based on measured solar data for locations such as Bet-Dagan, Israel [26], Surabaya, Indonesia [27] and Spain [28]. For other such locations, such as Hannover, Germany[29], Tehran, Iran [30] and South Africa [31], it was possible to determine the optimum fixed-collector positions based on data from photovoltaic panels. In these cases, the results based on measured solar data include the effects of pollution and the weather of the specific location.

The $\beta$ angle of the module and its position are very crucial for designing a solar system. As better explained in [32], the researches discussed the best performance, design, simulation for the solar energy system using optimum tilt angle. There are number of studies and researches that were carried out in order to find the best performance of solar system areas around the world, and others in a comparison between different locations. There are numerous applications regarding the optimum tilt angle for a specific geographic location, as for example photovoltaic system [33,34], solar still [35], solar powered thermoacoustic engines [36], building-integrated photovoltaic system (BIPV) [37,38], solar cooling [39], solar updraft tower power plant [40], and solar collectors[4144].

A number of studies were carried out to find the optimum tilt angle and orientation (azimuth) of PV systems, solar collectors, or any other application in certain areas around the world [32].

Indeed, from the review, it has been found that solar panels should be set at Optimal Tilt Angle (angle at which PV panel produces maximum power), as Performance Ratio of the system is very much dependent on tilt angle of the PV module [45]. For example in Sardinia [46], two PV plants are located at the same place, but one plant whereas grounded and another plant whereas roofmounted. The performance ratio of the roof-mounted PV plant (panel tilted at the optimal tilt angle) was more than the ground-mounted PV plant. Similarly, in Abu Dhabi [47], at Jaen [48], the same PV plants give a different performance at the same time due to the difference in tilt angle. Hence, before the installation of the generic solar plant, it is very important to find an optimal tilt angle and suitable positioning to get optimal results.

Indeed, as previously described, the optimum tilt-azimuth angles for a solar thermal system maximize the annual solar fraction of the system. Usually, solar thermal systems installed in warm climates are operated with a very elevated summer solar fraction with useful energy from the collector higher than required. It is feasible to increase the solar fraction of the system by increasing the useful energy in winter and decreasing the energy collected during summer, taking into account that this should not be lower than the load energy. This can be done by searching for a tilt angle that maximizes the annual solar fraction of the system [4] or for a fixed time. Seasonal or occasional use of the solar system for production of Domestic Hot Water (DHW), needs accurate, specific design but should not be based on the standard criteria generally applied to continuous use system, to avoid considerable over-sizing. It could be interesting to develop an accurate and easy-to-use procedure , to maximize the actual Solar Fraction (S.F.) and minimize the auxiliary energy $\left(Q_{A u x}\right)$, taking into account occasional use, seasonal and monthly DHW demand, orientation and primary flow rate.

For this reason, the authors propose a methodology that allows the identification of simple, reliable correlations that can immediately determine the best angle for occasional use. Thanks to the development of accurate case studies, it was possible to investigate that the reduction of $Q_{A u x}$ to a minimum is strongly linked to the $\beta$ angle and that the best position of the solar collector is a function of the period and of the solar irradiation. In this work, the authors identified some correlations characterized by a very simple form and a high value of the coefficient of determination $\left(\mathrm{R}^{2}\right)$, which permits the immediate identification of the best angle of solar collector installation for occasional use without any calculations or an expert user. 


\section{METHOD}

As previous indicated, optimal orientation is crucial in the case of seasonal or occasional use of the system; the choice of an incorrect position and the use of inaccurate or not optimal correlations related to systems designed for continuous use, in the long run, hinders the dissemination of renewable technologies.

The following work proposes an alternative method, replicable in all conditions and in all latitudes, to determine the optimal position of solar systems without knowing the indications dictated by the reference legislation or having specific knowledge in the field of solar design.

Although today there are different standards and guidelines that give indications on the procedures and criteria to be adopted in order to maximize the efficiency of solar systems, their use requires the presence of an expert user in the field of solar design or the use of simplified criteria systems that often invalidate the functioning of a solar system due to an oversizing and / or an extension of the payback times. Similarly, the use of specific mathematical models or numerical solutions requires specific software which is not always simple to use, lengthening and complicating the design phases. In an attempt to overcome these limits and accelerate the first design phases, the authors have tried to determine a criterion that in a simple and immediate way, without the request of an expert user and with a high reliability degree, allows to identify the optimal tilt that a solar system must have to guarantee high performance and low costs.

The methodology in fact led to the determination of simple mathematical correlations that can be solved in a simple and immediate way by knowing only some parameters that are easy to find, ensuring high reliability thanks to the determination of high $\mathrm{R}^{2}$ values.

Such a simple tool allows you to speed up the first stages of the design helping the technician to find the best solution especially for all situations in which a design must take into account occasional or seasonal use to avoid oversizing and therefore additional costs.

The method, validated for 9 cities in southern Italy and for the entire Sicilian region, can be replicated and adapted to any reality and latitude, guaranteeing a specific and targeted design for the purposes of the solar system. As can be seen from the results (Annex A) this approach allows to identify the optimal conditions which leads to an average annual saving of about $200 \mathrm{kWh}$, with an obvious positive result also in economic terms.

This methodology, if applied in other cities and latitudes, can represent a new criterion to be added in the guidelines of the solar system design; a simple collection of several equations that immediately calculate the best tilt to adopt especially for occasional use.”

To better understand the procedure and to guide the reader in the replication of this methodology in any condition and location, the flowchart outlines the main steps of the procedure which was followed for a specific case study: 


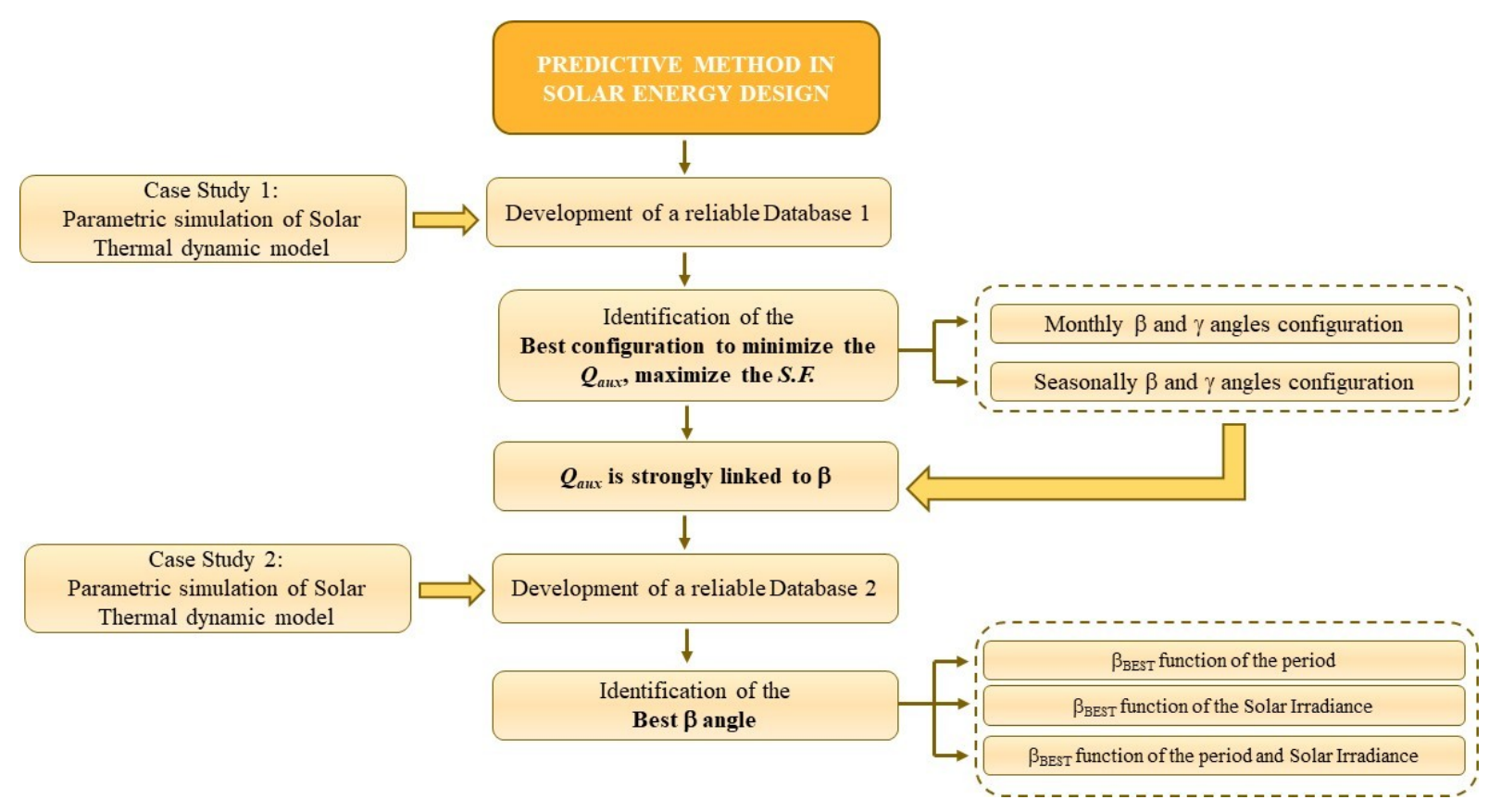

Fig. 1. Flowchart of the proposed procedure

The reliability of the entire procedure and of the obtained results is based on the data of a huge specific database developed ad hoc for a solar plant designed for real consumption.

More in detail, after the development of an "ideal case study" (section 3), a huge database obtained from a very large number of detailed dynamic simulations developed in the TRNSYS environment [49] was developed and analysed, in which several time series of physical parameters of the solar plant were accurately calculated. In the simulations, actual hourly consumption of DHW, variable over days and seasons, were employed. An extensive parametric analysis was carried out varying $\beta, \gamma$ angles and flow rate of the primary fluid (

$\left.m_{\text {coll }}\right)$. To produce a very detailed and precise time series, the time step of TRNSYS simulations was extremely short; consequently, the changes in the above parameters led to more than 10,000 simulations, developing a data matrix of more than $5.5 \times 10^{9}$ elements. To allow for better management of the data and a connection with an accurate statistical package (section 4), the extensive collection of data was imported into a MySQL database server.

First, the case study of the solar collector installed in the city of Palermo, a city in the South of Italy, characterized by a Mediterranean weather conditions with high values of solar irradiance, was analysed. This made it possible to identify the best configuration of the solar system that minimizes the $Q_{A u x}$ value in annual, seasonal and monthly time, and it the minimum $Q_{\text {Aux }}$ value was found to:

- $\quad$ correspond to the maximum of S.F.,

- be strongly dependent on the $\beta$ angle, but

- be practically independent of the $\gamma$ angle (section 5 ).

Based on these considerations, the authors decided to investigate whether it was possible to determine empirical correlations that could simply and immediately identify the tilt angle that maximizes the solar plant efficiency in occasional use, without any simulation tool or expert support (section 6).

A case study of solar collectors installed in Sicily was developed, implementing another solarenergy database which takes into account the same conditions used for the city of Palermo, but in this case was replicated for a total of nine Sicilian cities. Afterwards, the data output 
was extracted and processed, to help in the design of a solar thermal collector for the production of DHW even when use is fractionated and/or discontinuous.

In this case, the following are proposed:

- simple correlations to determine the best $\beta$ angle as a function of the month (section $6.2)$;

- simple correlations to determine the best $\beta$ angle as function of the solar irradiance (section 6.3);

- simple correlations to determine the best $\beta$ angle as a function of the month and solar irradiance (section 6.4).

As explained in Section 6, the reliability of the results is guaranteed by high values of the determination coefficient of all correlations. In this study, these correlations are valid for each analysed city and for the entire region of Sicily and issue a simple function of well-known, available parameters like monthly and seasonal solar irradiation. The strength of this work is that the positive results confirm that the proposed methodology can be replicated in any location. Indeed, the identification of simple correlations speeds up and helps, with a high degree of reliability, any first design phase during renewable energy planning

\section{SOLAR THERMAL DYNAMIC MODEL}

Hourly consumption data of DHW is essential for computing energy demand and for system sizing. Latitude, weather conditions, occupant number and behaviour, lifestyle, and social and economic conditions have been considered key variables in the literature [50-54]. An appropriate dimensioning should include a careful assessment of DHW as a function of the system's actual use [55,56], specifying whether the system provides for continuous, seasonal or occasional production and differencing hot water consumption during work days and at the weekend.

\subsection{Heat load analysis}

In order to propose an optimal design of a solar thermal system operating in specific time conditions, the authors, following the guidelines given in [55], have built the hourly trends of the annual DHW consumption per capita. Based on the daily average consumption for each month and on the hourly trends of a typical working day, the following trends have been built. These profiles have been adapted to the residential sector, considering an annual average consumption per capita of $70 \mathrm{l} /$ day at $45^{\circ} \mathrm{C}$ (Fig. 2).

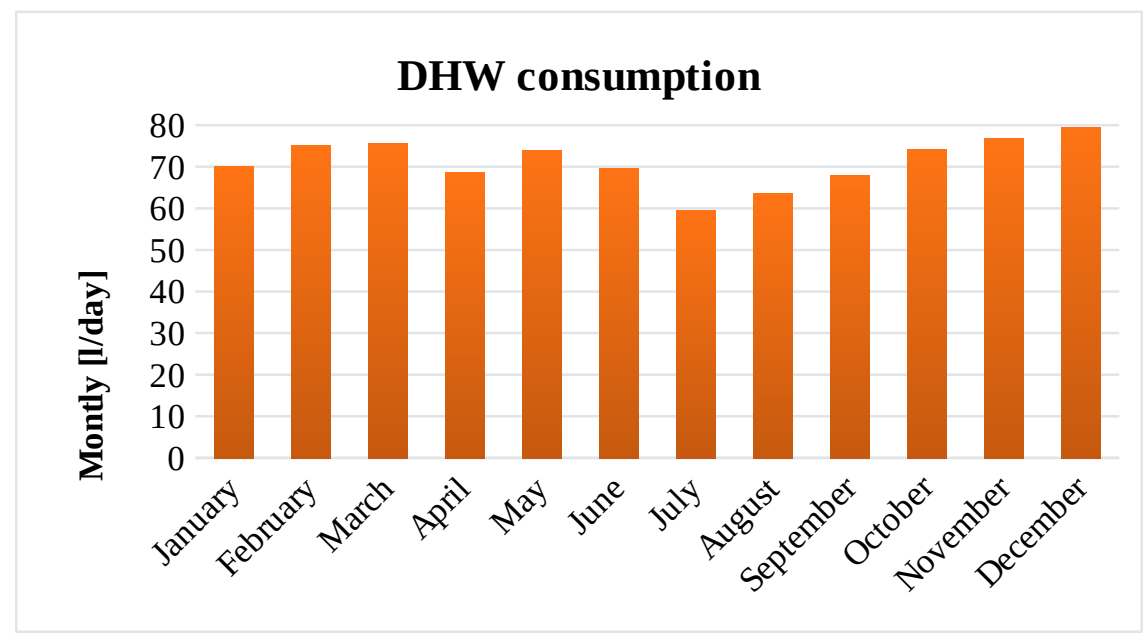


Fig. 2. Monthly DHW consumption per capita.

Based on the average daily consumption for each month and considering the generic load trend for the typical working day, the authors have built DHW weekly load profiles for each month. Furthermore, to determine the hourly trend of weekends and holidays, the authors have considered different user habits compared to work days.

\subsection{TRNSYS model}

To analyse the energy performance of a thermal solar system in the case of seasonal or occasional use, a detailed dynamic model was built in the TRNSYS environment; an internationally validated physical model has been implemented. In Fig. 3, the schema and the logic of the solar system dynamic model is shown.

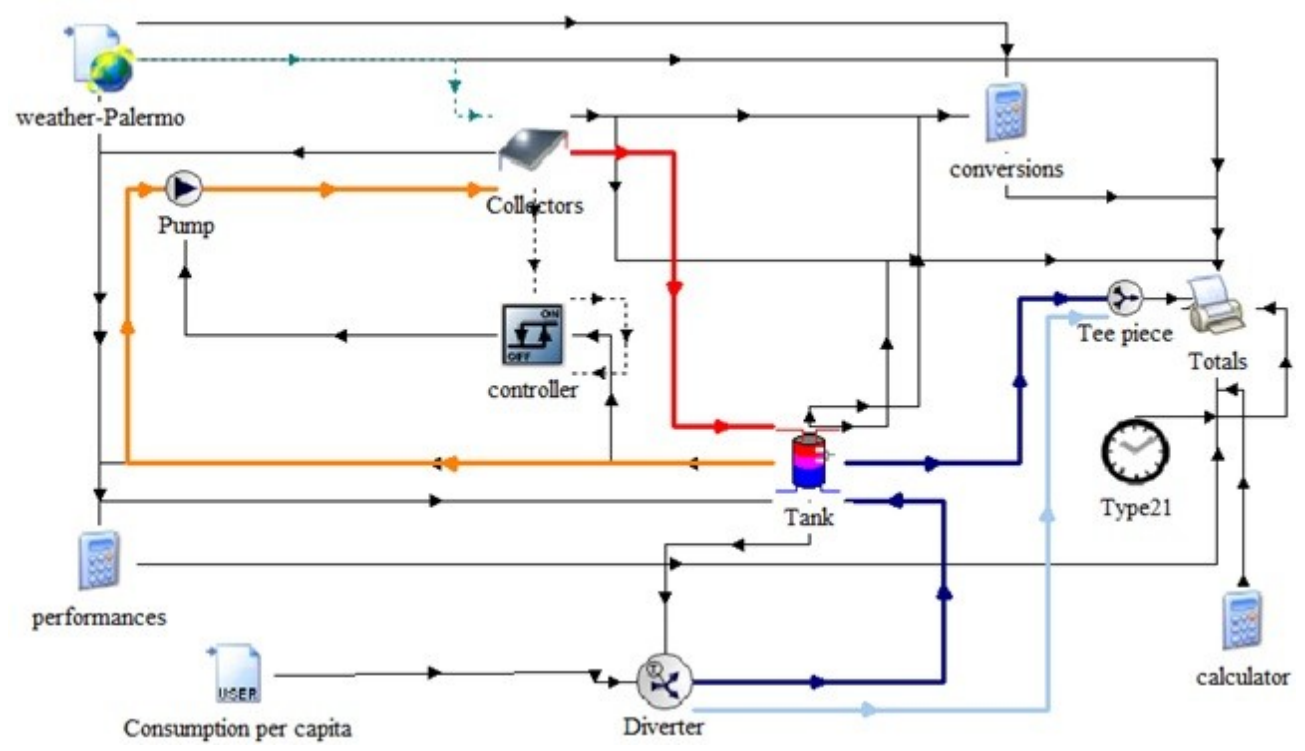

Fig. 3. Solar Thermal TRNSYS model.

The analysed system consists of two interconnected circuits through a heat exchange coil located in the storage tank (Type 60d) of the solar system. The primary circuit (orange and red lines) is characterized by a constant-flow circulator (Type 3d) and by a solar collector surface (Type 1b). To avoid winter freezing phenomena, a $10 \%$ glycol-water mixture as thermal fluid was used. The parameters of the solar collector system used in the study are reported in Table 1: aHeliodyne Inc. Gobi 410002 solar collector [57].

\section{Table 1}

Solar collector technical parameter (Type 1b).

\begin{tabular}{lc}
\hline Parameter & Value \\
\hline Collector Area $\left[\mathrm{m}^{2}\right]$ & 3.73 \\
Thermal fluid specific heat $[\mathrm{kJ} /(\mathrm{kg} \mathrm{K})]$ & 4.02 \\
Intercept efficiency & 0.72 \\
Efficiency slope [\%] & 19.12 \\
$1^{\text {st }}$-order IAM & 0.09 \\
$2^{\text {nd }}$-order IAM & 0 \\
Number in series & 1 \\
\hline
\end{tabular}


For safety reasons, the circulator is automatically regulated by a controller (Type 2b). To promote water stratification, a vertical cylindrical outdoor tank was chosen. In addition, to assess the degree of thermal stratification inside the tank, the temperature was monitored at ten different nodes which were equally distributed.

Inside the tank, to heat the water at $0.40 \mathrm{~m}$ from the bottom part of the tank when the solar source is not sufficient, there is an auxiliary electric resistance of $1.5 \mathrm{~kW}$. The resistance turns-on when the control system reads a water temperature value at the highest node below or equal to $50{ }^{\circ} \mathrm{C}$ and turns-off when the water reaches a temperature of $55^{\circ} \mathrm{C}$. Table 2 shows the main features of the storage tank modelled in TRNSYS [58].

\section{Table 2}

Storage tank technical parameters (Type 60d).

\begin{tabular}{lcl}
\hline \multicolumn{1}{c}{ Parameter } & Value & Unit \\
\hline Tank volume & 0.383 & {$\left[\mathrm{~m}^{3}\right]$} \\
Tank height & 1.7 & {$[\mathrm{~m}]$} \\
Height of flow inlet & 0.05 & {$[\mathrm{~m}]$} \\
Height of flow outlet & 1.65 & {$[\mathrm{~m}]$} \\
Thermal fluid specific heat & 4.190 & {$[\mathrm{~kJ} /(\mathrm{kg} \mathrm{K})]$} \\
Tank loss coefficient & 0.5 & {$\left[\mathrm{~W} /\left(\mathrm{m}^{2} \mathrm{~K}\right)\right]$} \\
Fluid Thermal conductivity & 0.389 & {$[\mathrm{~W} /(\mathrm{m} \mathrm{K})]$} \\
Height auxiliary heater & 0.40 & {$[\mathrm{~m}]$} \\
Height thermostat & 1.65 & {$[\mathrm{~m}]$} \\
Set point temperature & 55 & {$\left[{ }^{\circ} \mathrm{C}\right]$} \\
Dead band for heating element & 5 & {$\left[{ }^{\circ} \mathrm{C}\right]$} \\
Maximum heating rate & 1.5 & {$[\mathrm{~kW}]$} \\
Heat exchanger inside diameter & 0.022 & {$[\mathrm{~m}]$} \\
Heat exchanger outside diameter & 0.023 & {$[\mathrm{~m}]$} \\
Heat exchanger fin diameter & 0.023 & {$[\mathrm{~m}]$} \\
Total surface area of heat exchanger & 1.23 & {$\left[\mathrm{~m}^{2}\right]$} \\
Heat exchanger wall conductivity & 300 & {$[\mathrm{~W} /(\mathrm{m} \mathrm{K})]$} \\
Heat exchanger material conductivity & 200 & {$[\mathrm{~W} /(\mathrm{m} \mathrm{K})]$} \\
Height of heat exchanger inlet & 0.85 & {$[\mathrm{~m}]$} \\
Height of heat exchanger outlet & 0.05 & {$[\mathrm{~m}]$}
\end{tabular}

In the secondary circuit (blue and light-blue lines), in which the water comes from a well and the users service, a deviating valve (Type 11b) and a mixing valve (Type 11h) can be identified.

The water temperature in the well, in the TRNSYS model, is linked to the seasonal temperature of the soil. The aim of the diverting valve is to make the water reach a temperature of $45^{\circ} \mathrm{C}$. In the blue line, the flow warms when it is in contact with the coil, whereas in the light-blue line the flow, bypassing the tank, is directed to the mixing valve. Under these conditions, it is necessary to evaluate the efficiency of the solar collector and the S.F. values. The efficiency of the solar collector is defined according to Eq. (1):

$\eta_{\text {coll }}=\frac{E_{\text {gain }}}{A_{\text {coll }} \cdot I}$

where $E_{\text {gain }}$ is the instantaneous thermal power collected by the panel $[\mathrm{kW}], A_{\text {coll }}$ is the collector area $\left[\mathrm{m}^{2}\right]$ and $I$ the incident irradiation $\left[\mathrm{kW} / \mathrm{m}^{2}\right]$. 
Generally, S.F. is defined as the ratio of useful solar energy supplied to the system to the energy needed to heat water if no solar energy is used [59]. In other words, if we consider

$Q_{\text {Awx }}$ the auxiliary power and $Q_{\text {load }}$ the load power obtained as:

$Q_{\text {Ioad }}=m_{\text {Ioad }} C_{p} \Delta T$

where $m_{\text {lood }}$ is the flow rate $[\mathrm{kg} / \mathrm{s}] ; c_{p}$ is the specific heat of the water $[\mathrm{kJ} / \mathrm{kgK}]$ and $\Delta T$ is the difference temperature between the output flow rate and the well-water flow rate at the user, the S.F. can be written as Eq. (3):

S.F. $=1-\left(\frac{Q_{\text {Aux }}}{Q_{\text {load }}}\right)$

The model was simulated with a time step of $0.25 \mathrm{~h}$; the reason for such a short time step was so that the stratification phenomenon in the storage tank could be investigated thoroughly. From each simulation, the characteristic thermal data of the solar system and some weather data, such as horizontal solar irradiance, incident solar irradiance on the collector surface and external temperature were recorded.

\section{DATABASE CREATION}

In order to obtain a database that represents the most general operating conditions leading to the determination of the best solar system configuration for seasonal and/or occasional use, the authors decided to develop an ad hoc database, determining the energy performance of the solar collector in the city of Palermo, Lat. $38.1131^{\circ} \mathrm{N}$, Sicily, Southern Italy.

The solar system satisfies the required thermal load for a family of 4 people, expecting to reach S.F. $=1$ in summer.

Thanks to a parametric simulation, 10,323 simulations were implemented. To be specific, for the following variables, all conditions based on the variation ranges and the calculation steps of the tilt angle, azimuth angle and flow rate of the primary circuit were simulated, as indicated in Table 3.

Table 3

Variables range and step.

\begin{tabular}{ccccc}
\hline Variable & Minimum & Maximum & Step & Step number \\
\hline$\beta\left[^{\circ}\right]$ & 0 & 90 & 3 & 31 \\
$\gamma\left[^{\circ}\right]$ & -90 & 90 & 5 & 37 \\
$m_{c o \|}[\mathrm{kg} / \mathrm{h}]$ & 80 & 240 & 20 & 9 \\
\hline
\end{tabular}

In Southern Italy, climatic conditions are characterized by high solar irradiance values for a large part of the year, and this leads to a value of S.F. $=1$ for most of the year. To better identify the unique orientations that maximize the S.F. and minimize the $Q_{\text {Aur }}$ values, the 
solar system was simulated to provide a thermal load 2 times greater than that required by a single family of 4 people.

The simulations were carried out with TRNSYS software installed on a machine with Intel core i7 4790 4core with $3.6 \mathrm{GHz}$ processor and $28 \mathrm{~GB}$ of RAM; the time required to make the 10,323 simulations was about 48 hours.

The results from the TRNSYS simulations compose the reference database; since each simulation was performed with a time step of $0.25 \mathrm{~h}$, each model allows the recording of 35,040 values for each selected output parameter. Thus, in order to streamline the evaluation and analysis of the data, these values were averaged for each hour.

In this way, the global output of the process produces more than $150 \mathrm{~GB}$ of text. As a result, the authors chose to use a MySQL database server to better manage this big data. The use of primary keys and indexes on columns by day, month and hour allowed a significant increase in response performance of the queries used.

The meaning of each parameter is better explained in the following:

- $\quad I d$ : primary key;

- Simul.: simulation number (from 1 to 10,323);

- Hour: daily hour (from 1 to 24);

- Day: day of the month;

- Month: month of the year (from 1 to 12 );

- $T_{\text {outcoll: }}$ outlet temperature of the solar collector $\left[{ }^{\circ} \mathrm{C}\right]$;

- $T_{\text {outHX: outlet temperature of heat exchanger }\left[{ }^{\circ} \mathrm{C}\right] \text {; }}$

- $T_{\text {user }}$ : temperature required by the user $\left[{ }^{\circ} \mathrm{C}\right]$;

- $\quad I$ : incident solar irradiance on the collector surface $\left[\mathrm{kW} / \mathrm{m}^{2}\right]$;

- $\quad m_{\text {coll }}$ : water-glycol flow rate $[\mathrm{kg} / \mathrm{s}]$;

- $\dot{Q} Q_{\text {Aux }}$ : auxiliary power $[\mathrm{kW}]$;

- $T_{\text {tank: }}$ : tank average temperature $\left[{ }^{\circ} \mathrm{C}\right]$;

- $\eta_{\text {coll: }}$ collector efficiency;

- $\quad$ S.F.: solar fraction;

- $T_{\text {ext }}$ : external temperature $\left[{ }^{\circ} \mathrm{C}\right]$.

The data output was extracted and processed to determine the best configuration of tilt angle $\beta$ $\left[{ }^{\circ}\right]$ and Azimuth angle $\left.\gamma^{\circ}{ }^{\circ}\right]$ that can help to design a solar thermal collector for the production of DHW even when the use is fractionated and/or discontinuous. A first comparison of the three variables $\left(\beta, \gamma, m_{\text {coll }}\right)$ shows that S.F. and $Q_{A u x}$ values are highly dependent on $\beta$ and $\gamma$ angles and are less dependent on the $m_{c o \|}$. To highlight this phenomenon, Fig. 4 shows that the flow rate is practically constant at the variation of the $\gamma$ or $\beta$, both in the case of S.F. and in the case of $Q_{\text {Aux }}$.

$$
\text { S.F. } \mathbf{f}\left(\gamma, \mathbf{m}_{\text {coll }}\right)
$$

$Q_{\text {Aux }} \mathbf{f}\left(\gamma, \mathbf{m}_{\text {coll }}\right)-$ 


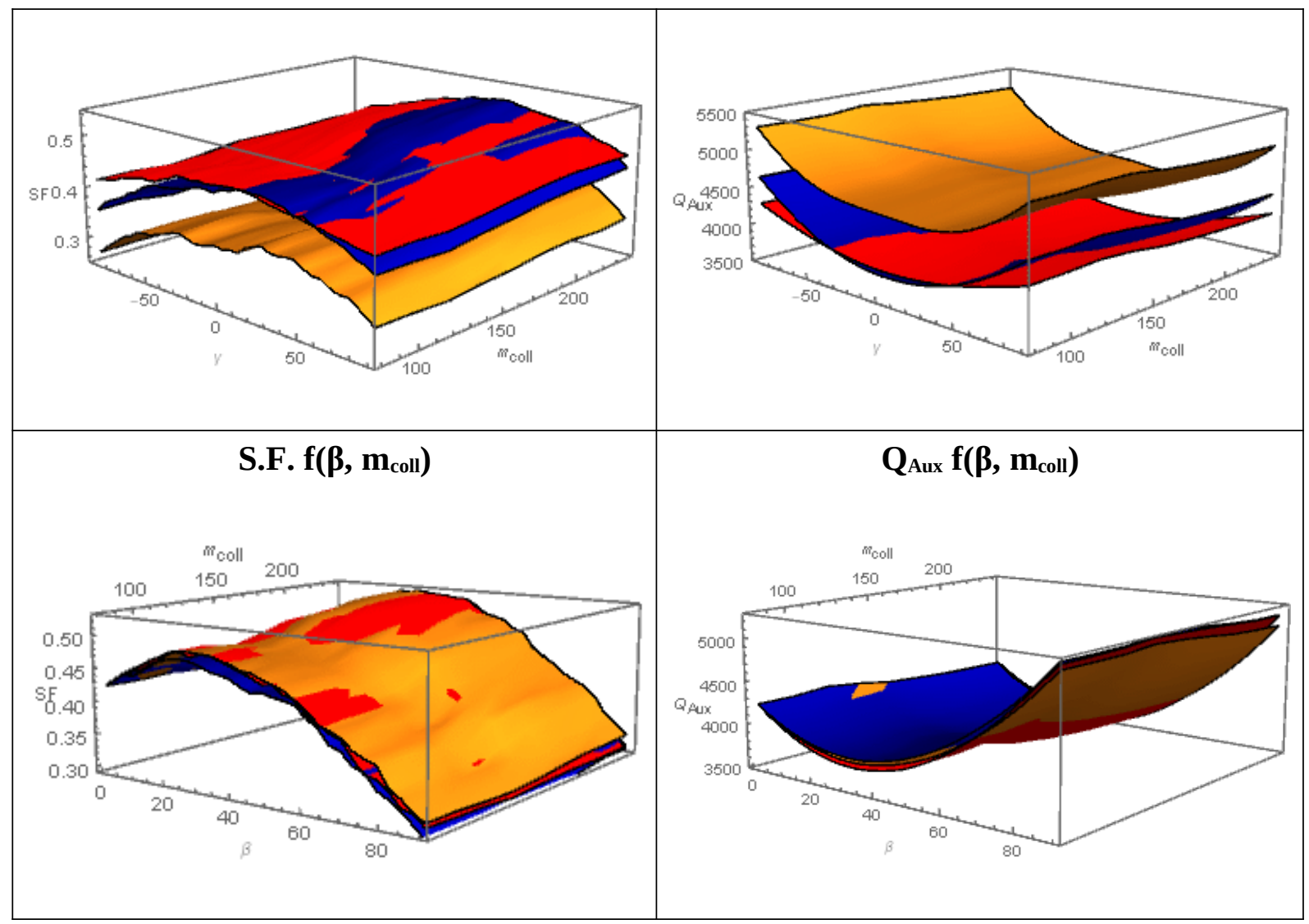

Fig. 4. $Q_{\text {Aux }}$ and S.F. surfaces functions of $\left(\beta, m_{\text {coll }}\right)$ and of $\left(\gamma, m_{c o l l}\right)$.

More specifically, in the upper part, the S.F. and $Q_{\text {Aux }}$ surfaces for three constant values of $\beta\left(15^{\circ}\right.$ in red, $45^{\circ}$ in blue and $75^{\circ}$ in yellow) are plotted, while in the lower part the S.F. and $Q_{\text {Aux }}$ surfaces for three constant value of $\gamma\left(0^{\circ}\right.$ in red, $-30^{\circ}$ in blue and $30^{\circ}$ in yellow) are shown.

It was decided to carry out an analysis imposing a fixed flow-rate of $200 \mathrm{l} / \mathrm{h}$ as suggested in the technical sheet from the manufacturer [57].

Based on the previous considerations, the dependence of S.F. and $Q_{A u x}$ only on $\gamma$ and $\beta$ was analysed.

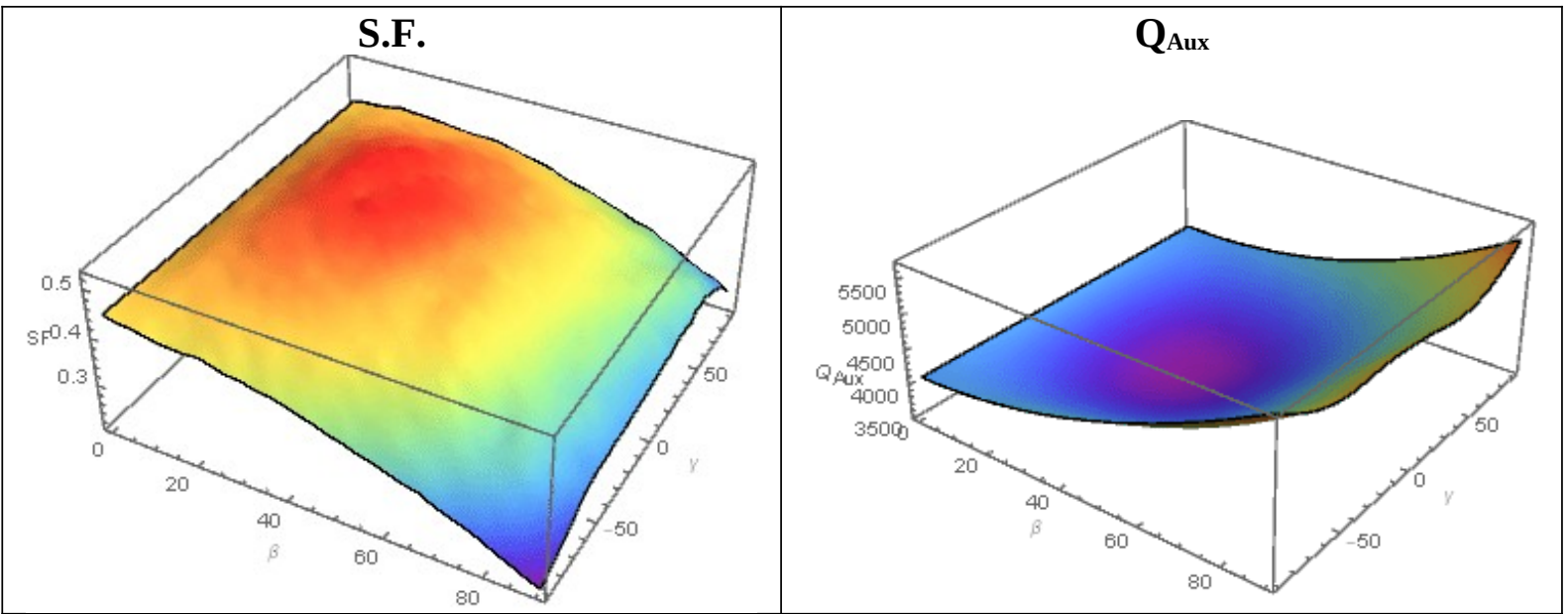

Fig. 5. Annual surface of S.F. and $Q_{\text {Aux }}$. 
In Fig. 5, the annual S.F. and $Q_{\text {Aux }}$ surfaces are plotted; the annual charts show that the surfaces created as a function of $\beta$ and $\gamma$ have very similar trends to quadric functions. The maximum S.F. value and the minimum $Q_{\text {Aux }}$ value are related respectively to the $\gamma$ value close to zero and to the $\beta$ value close to the latitude of the site.

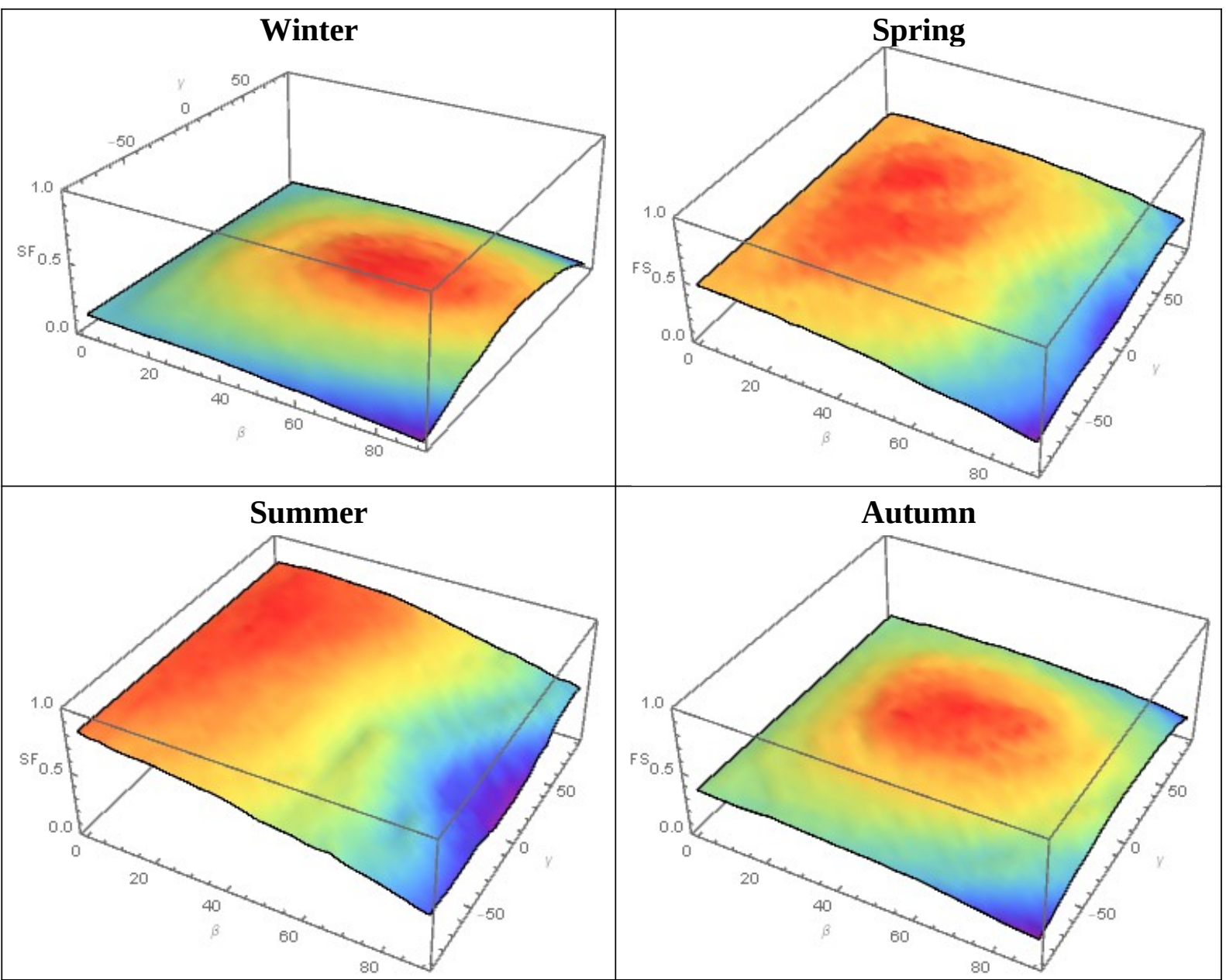

Fig. 6. Seasonal surface of S.F.

Figures 6 and 7 show the surfaces of S.F. and $Q_{\text {Aux }}$ for the four seasons; S.F. seasonal charts show how for all seasons the maximum S.F. value is always close to $\gamma=0^{\circ}$ (South orientation). Instead, the $\beta$ angle varies with the seasons: from a minimum of $10-15^{\circ}$ in the summer period, corresponding to an S.F. value close to 0.9 , to a maximum of $60^{\circ}$ during the winter with an S.F.= 0.3 .

\section{Winter}

\section{Spring}




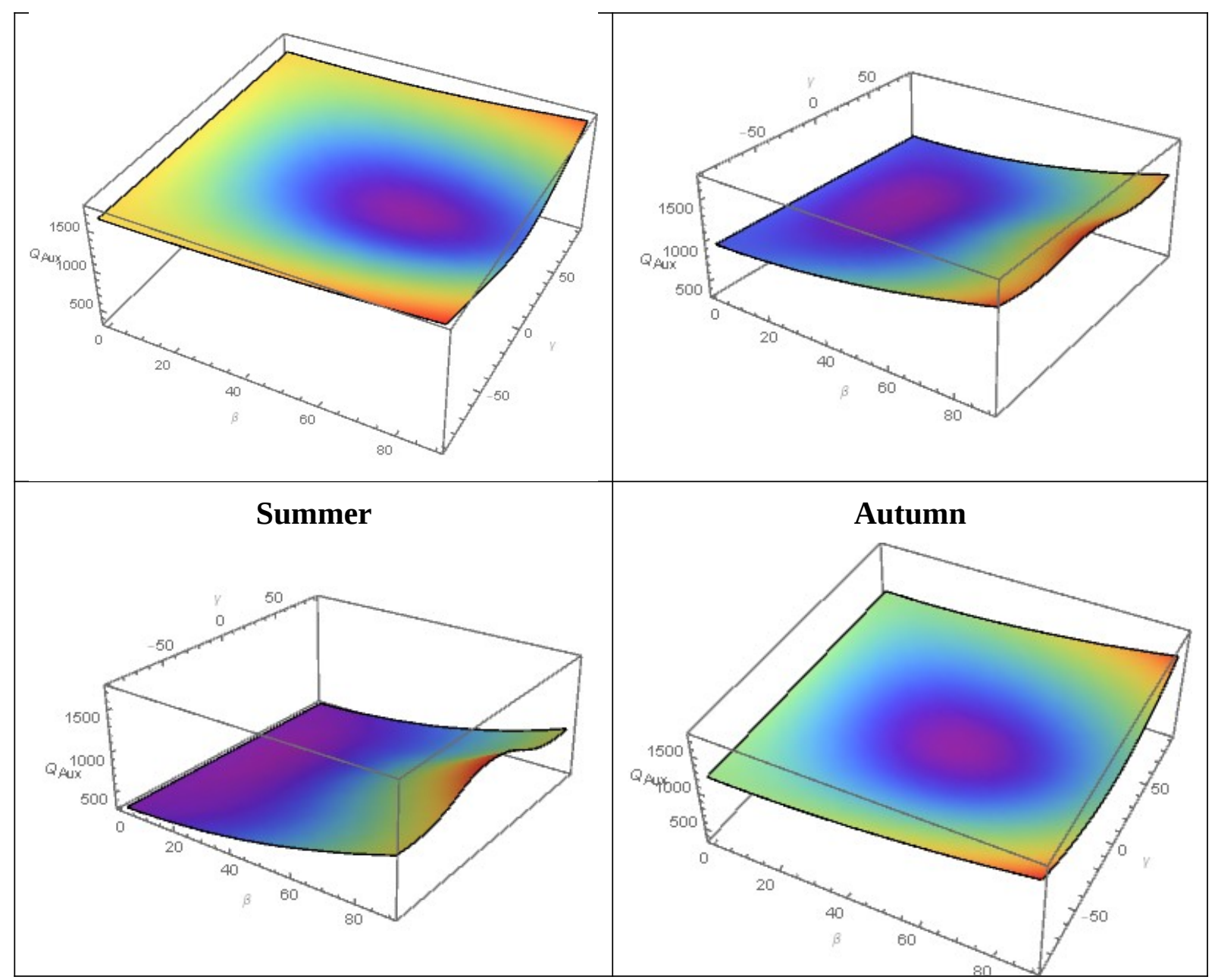

Fig. 7. Seasonal surface of $\mathrm{Q}_{\text {Aux. }}$.

As expected, $Q_{\text {Aux }}$ seasonal charts show opposite surface plots with respect to the surfaces in Fig. 6. The choice of the city of Palermo, in Southern Italy allows the determination of a maximum value of $Q_{A u x}$ at around $1250 \mathrm{kWh}$ in winter and about $300 \mathrm{kWh}$ in summer.

\section{IDENTIFICATION OF THE BEST CONFIGURATION}

Based on good design rules [40], in Italy to maximize the solar system efficiency, the collectors are oriented to the south and tilted at the same latitude as the site; a very generic indication for non-continuous use is to add $+15^{\circ}$ for winter and $-15^{\circ}$ for summer. For the city of Palermo (Latitude: $38^{\circ} \mathrm{N}$ ), this practice suggests the following $\beta$ angles:

- $\quad$ Spring and Autumn: $+38^{\circ}$;

- Winter: $+53^{\circ}$;

- Summer: $+23^{\circ}$.

As indicated above, in Southern Italy, climatic conditions are characterized by high solar radiation values for a long time and the value of S.F. could be 1 for most of the year.

The authors, analysed the data from simulations to identify the best configuration of the solar system that minimizes the $Q_{\text {Aux }}$ value, on annual, seasonal and monthly time use.

Comparing the data suggested by practical use with data coming from detailed simulations (optimal), it was possible to outline that, for annual installation, the optimal $\beta$ angle is $+38^{\circ}$ and $Q_{A u x}=3558 \mathrm{kWh}$ versus $+33^{\circ}$ and $Q_{A u x}=3531 \mathrm{kWh}$ respectively, while the $\gamma$ angle is the same $0^{\circ}$. On a seasonal basis, the following results are obtained: 


\section{Table 4}

Seasonal $\beta$ and $\gamma$ angles for optimal configuration.

\begin{tabular}{lcccc}
\hline \multirow{2}{*}{ Optimal } & \multicolumn{2}{c}{ Practical use } & \multicolumn{2}{c}{ Optimal } \\
\cline { 2 - 5 } Configuration & $\boldsymbol{\beta}$ & $\boldsymbol{\gamma}$ & $\boldsymbol{\beta}$ & $\boldsymbol{\gamma}$ \\
\cline { 2 - 5 } Spring & $38^{\circ}$ & $0^{\circ}$ & $24^{\circ}$ & $25^{\circ}$ \\
Summer & $23^{\circ}$ & $0^{\circ}$ & $12^{\circ}$ & $10^{\circ}$ \\
Autumn & $38^{\circ}$ & $0^{\circ}$ & $48^{\circ}$ & $0^{\circ}$ \\
Winter & $58^{\circ}$ & $0^{\circ}$ & $60^{\circ}$ & $5^{\circ}$ \\
\hline
\end{tabular}

Table 4 shows that, to really minimize the $Q_{\text {Aux }}$, it is necessary to change simultaneously the $\beta$ and $\gamma$ angles.

A detailed analysis of the results and the application of Eq. (3) allowed the determination of couples of $(\beta, \gamma)$ that identify the minimum $Q_{\text {Aux }}$ value corresponding to the maximum of S.F, as shown in Table 5:

\section{Table 5}

Monthly $\beta$ and $\gamma$ angles for optimal configuration.

\begin{tabular}{lcccc}
\hline \multirow{2}{*}{$\begin{array}{l}\text { Optimal } \\
\text { Configuration }\end{array}$} & $\mathbf{Q}_{\text {Aux }}$ & S.F. & $\boldsymbol{\beta}$ & $\boldsymbol{\gamma}$ \\
\cline { 2 - 5 } & {$[\mathbf{k W h}]$} & {$[-]$} & {$\left[{ }^{\circ}\right]$} & {$\left[{ }^{\circ}\right]$} \\
\hline January & 405.18 & 0.50 & 63 & 5 \\
February & 403.90 & 0.45 & 51 & 5 \\
March & 376.81 & 0.53 & 39 & 10 \\
April & 260.54 & 0.67 & 24 & 15 \\
May & 215.10 & 0.73 & 15 & 30 \\
June & 139.23 & 0.82 & 6 & 0 \\
July & 44.18 & 0.95 & 9 & 10 \\
August & 104.35 & 0.87 & 18 & 15 \\
September & 207.62 & 0.73 & 33 & 0 \\
October & 301.63 & 0.63 & 48 & 0 \\
November & 369.84 & 0.53 & 60 & 0 \\
December & 459.04 & 0.43 & 66 & 5 \\
\hline
\end{tabular}

A positive value of $\gamma$ from $0^{\circ}$ to $30^{\circ}$ was always obtained and this condition is related to the asymmetric distribution on the load during the day.

Plotting the data collected in Table 5 on a graph, it is possible to see the following monthly $Q_{\text {Aux }}$ and S.F. trends: 


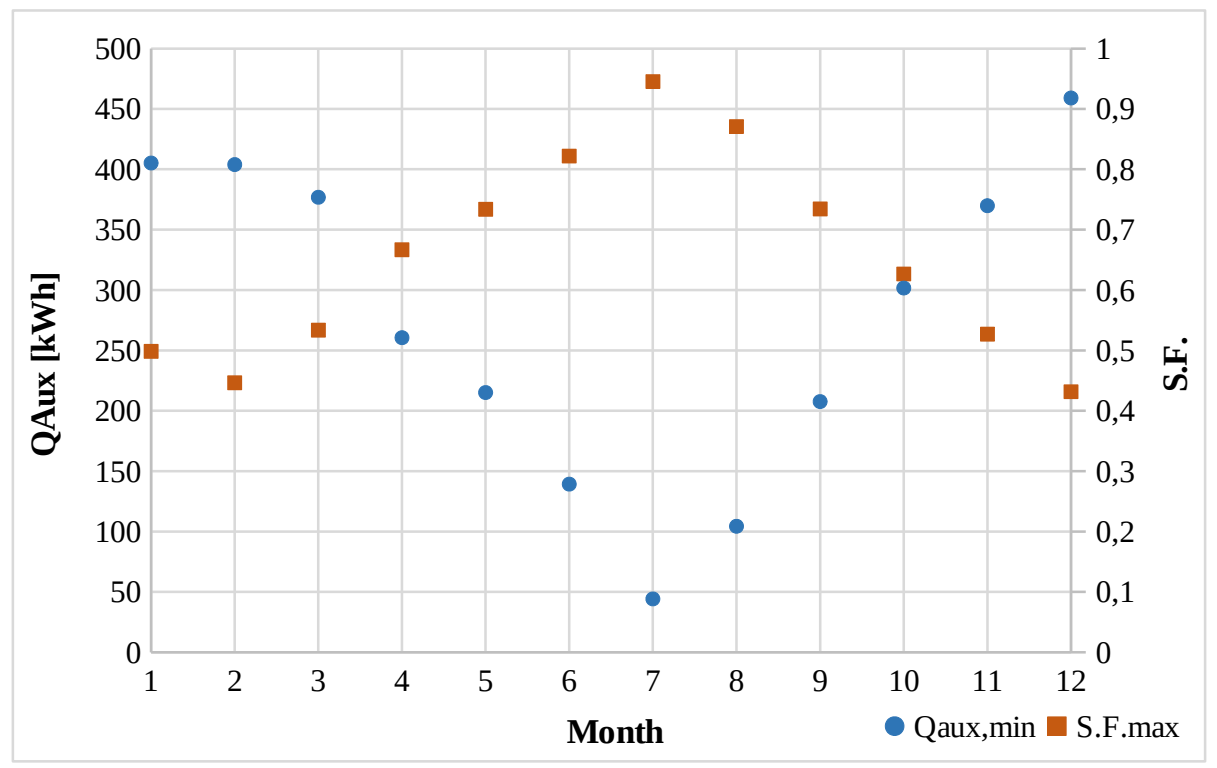

Fig. 8. Monthly $Q_{A u x}$ and S.F. trends.

Figure 8 shows that the maximum monthly S.F. value is in July $(S . F .=0.95)$ and corresponds to the minimum monthly $Q_{\text {Aux }}$ value of $44.2 \mathrm{kWh}$; on the contrary in December, the minimum monthly S.F. $=0.43$ corresponds to the maximum monthly $Q_{\text {Aux }}=459 \mathrm{kWh}$.

Furthermore, $Q_{A u x}$ values are strongly dependent on the $\beta$ angle but practically independent of the $\gamma$ angle. Figure 9 shows that the $Q_{A u x}$ when changing the $\gamma$ angle variation from $0^{\circ}$ to $30^{\circ}$ is very near to the $Q_{A u x}$ calculated for the optimal conditions. In particular, the $Q_{\text {Aux }}\left(\gamma=0^{\circ}\right) \approx Q_{\text {Aux }}(\gamma=$ optimum $)$; in this case the authors calculated a deviation of about $0.34 \%$.

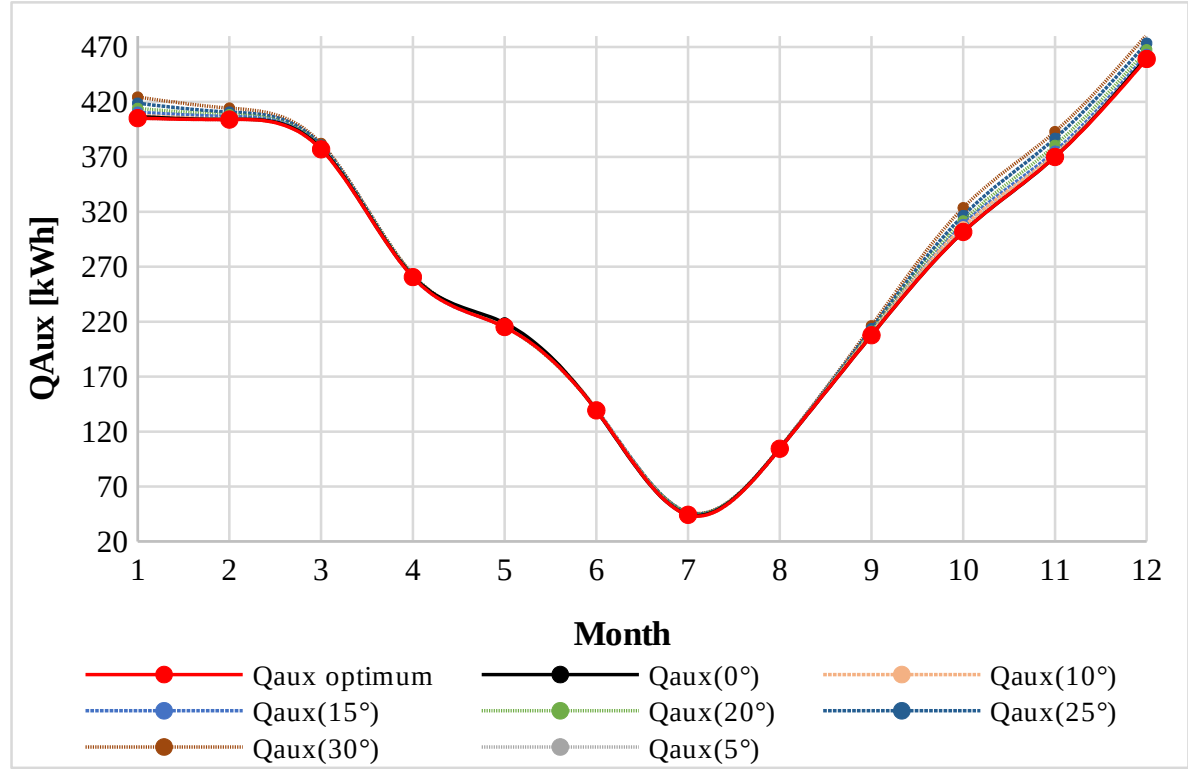

Fig.9. Monthly $Q_{\text {Aux }}$ trend for different $\beta$ angles (from $0^{\circ}$ to $30^{\circ}$ ).

Based on the above considerations, the authors evaluated the optimal configuration for the case study imposing $\gamma=0^{\circ}$; the results are collected in Table 6 . 
Table 6

Monthly $\beta$ and $\gamma=0^{\circ}$ angles for best configuration.

\begin{tabular}{lcccc}
\hline Optimal & $\mathbf{Q}_{\text {Aux }}$ & S.F. & $\boldsymbol{\beta}$ & $\gamma$ \\
\cline { 2 - 5 } Configuration & {$[\mathbf{k W h}]$} & {$[-]$} & $\left.{ }^{\circ}\right]$ & {$\left[^{\circ}\right]$} \\
\hline January & 406.62 & 0.50 & 63 & 0 \\
February & 404.12 & 0.45 & 51 & 0 \\
March & 377.72 & 0.53 & 42 & 0 \\
April & 261.37 & 0.67 & 24 & 0 \\
May & 218.82 & 0.73 & 12 & 0 \\
June & 139.23 & 0.82 & 6 & 0 \\
July & 44.56 & 0.94 & 9 & 0 \\
August & 104.54 & 0.87 & 18 & 0 \\
September & 207.62 & 0.73 & 33 & 0 \\
October & 301.63 & 0.63 & 48 & 0 \\
November & 369.84 & 0.53 & 60 & 0 \\
December & 460.70 & 0.43 & 66 & 0 \\
\hline
\end{tabular}

\section{THE $\beta_{\text {BEST }}$ ANGLE IN SICILY}

Taking the previous observations into account, the authors decided to identify one or more empirical correlations that allow the simple and immediate determination of the tilt angle that maximizes the efficiency of the solar-plant also in the case of occasional, seasonal and monthly use.

Moreover, as the efficiency of a solar collector also depends on the climatic conditions of the place, the authors have identified correlations that allow the identification of the best tilt also as a function of the solar irradiation. This analysis has been carried out for the nine provincial capital cities of Sicily.

\subsection{Case Study description}

Sicily is the largest island in Italy, located in the central Mediterranean Sea, south of the Italian Peninsula, from which it is separated by the narrow Strait of Messina. The island has a typical Mediterranean climate, with mild, wet winters and hot, dry summers with very changeable intermediate seasons. On the coasts, especially the south-western, the climate is affected by African air currents and summers can be scorching. Sicily is seen as an island of warm winters, but winters can be cold, above all along the Tyrrhenian coast and in inland areas which have a typical continental climate. Snow falls in abundance above 900 - 1000 metres, but stronger cold airwaves can easily carry it into the hills and even to coastal cities, especially on the northern coast of the island. The interior mountains, especially the Nebrodi, the Madonie and Etna, enjoy a fully mountain climate with heavy snowfalls during winter. The summit of Mount Etna is usually snow-capped from October to May. On the other hand, especially in the summer, it is not unusual to have the "Scirocco" wind from the Sahara. Rainfall is scarce and water proves deficient in some provinces where a water crisis can occur. Administratively, Sicily is divided into nine provinces: Agrigento, Caltanissetta, Catania, Enna, Messina, Palermo, Ragusa, Siracusa and Trapani (Fig. 10). 


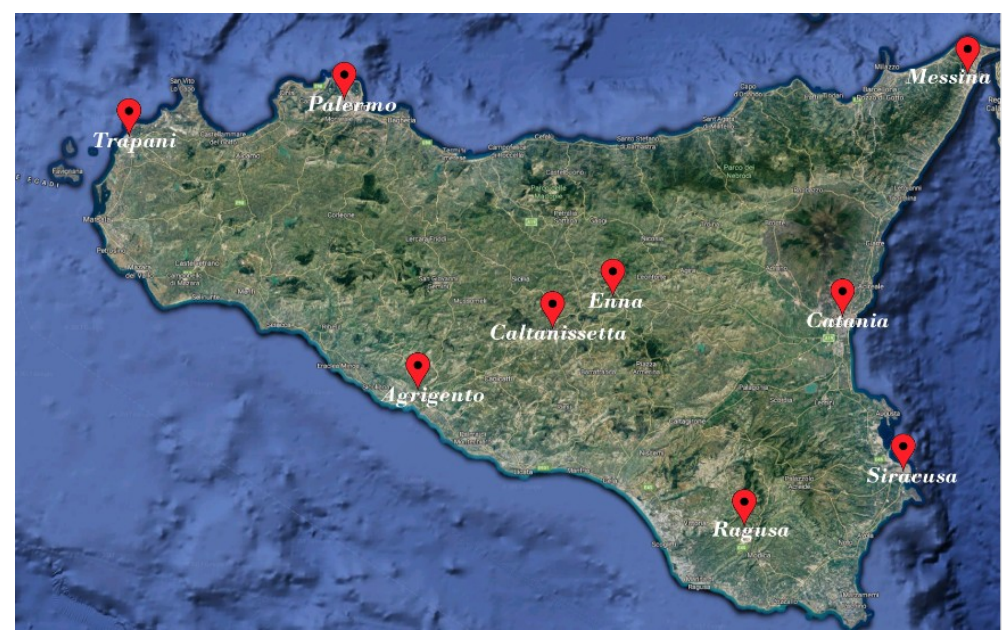

Fig. 10. Sicilian province cities.

From the UNI 10349:2016 [60], each city is characterized by the parameters summarized in Table 7:

\section{Table 7}

Characteristic parameters of the nine Sicilian province cities.

\begin{tabular}{lccccc}
\hline City & Latitude & $\begin{array}{c}\text { Average } \\
\text { Temperature }\end{array}$ & $\begin{array}{c}\text { Average horizontal solar } \\
\text { Irradiation }\end{array}$ & HDD & CDD \\
\hline & {$\left[{ }^{\circ} \mathbf{}\right]$} & {$\left[{ }^{\circ} \mathbf{C}\right]$} & {$\left[\mathbf{k W h} / \mathbf{m}^{2}\right]$} & {$\left[^{\circ} \mathbf{C}\right]$} & {$\left[{ }^{\circ} \mathbf{C}\right]$} \\
\hline Agrigento & 37.30 & 17.8 & 4.71 & 1186 & 79 \\
Caltanissetta & 37.48 & 17.7 & 4.54 & 1395 & 223 \\
Catania & 37.50 & 17.9 & 4.62 & 1265 & 161 \\
Enna & 37.55 & 15.9 & 4.65 & 1802 & 231 \\
Messina & 38.18 & 17.9 & 4.26 & 1262 & 143 \\
Palermo & 38.12 & 18.8 & 4.60 & 1121 & 166 \\
Ragusa & 36.92 & 15.0 & 4.77 & 1875 & 75 \\
Siracusa & 37.07 & 17.6 & 4.60 & 1398 & 276 \\
Trapani & 38.02 & 17.6 & 4.71 & 1343 & 163 \\
\hline
\end{tabular}

For each city, the Latitude, yearly average temperature, yearly average solar radiation, and the Heating and Cooling Degree Days (HDD and CDD) were collected; the last two parameters were calculated from $15^{\text {th }}$ October to $15^{\text {th }}$ April and from $16^{\text {th }}$ April and $14^{\text {th }}$ October respectively.

To identify the optimal design of a solar thermal system operating in specific time conditions, the authors built the hourly trends of the annual DHW consumption per capita for a typical Sicilian family, considering:

- an annual average consumption per capita of $70 \mathrm{l} /$ day at $45^{\circ} \mathrm{C}$, as indicated in Fig. 2;

- a variable average daily consumption for each month; and

- the generic load trend for the typical working day.

DHW weekly load profiles for each day and for each month were built; in Fig. 11, the daily load profiles in January related to 8 people are shown. 


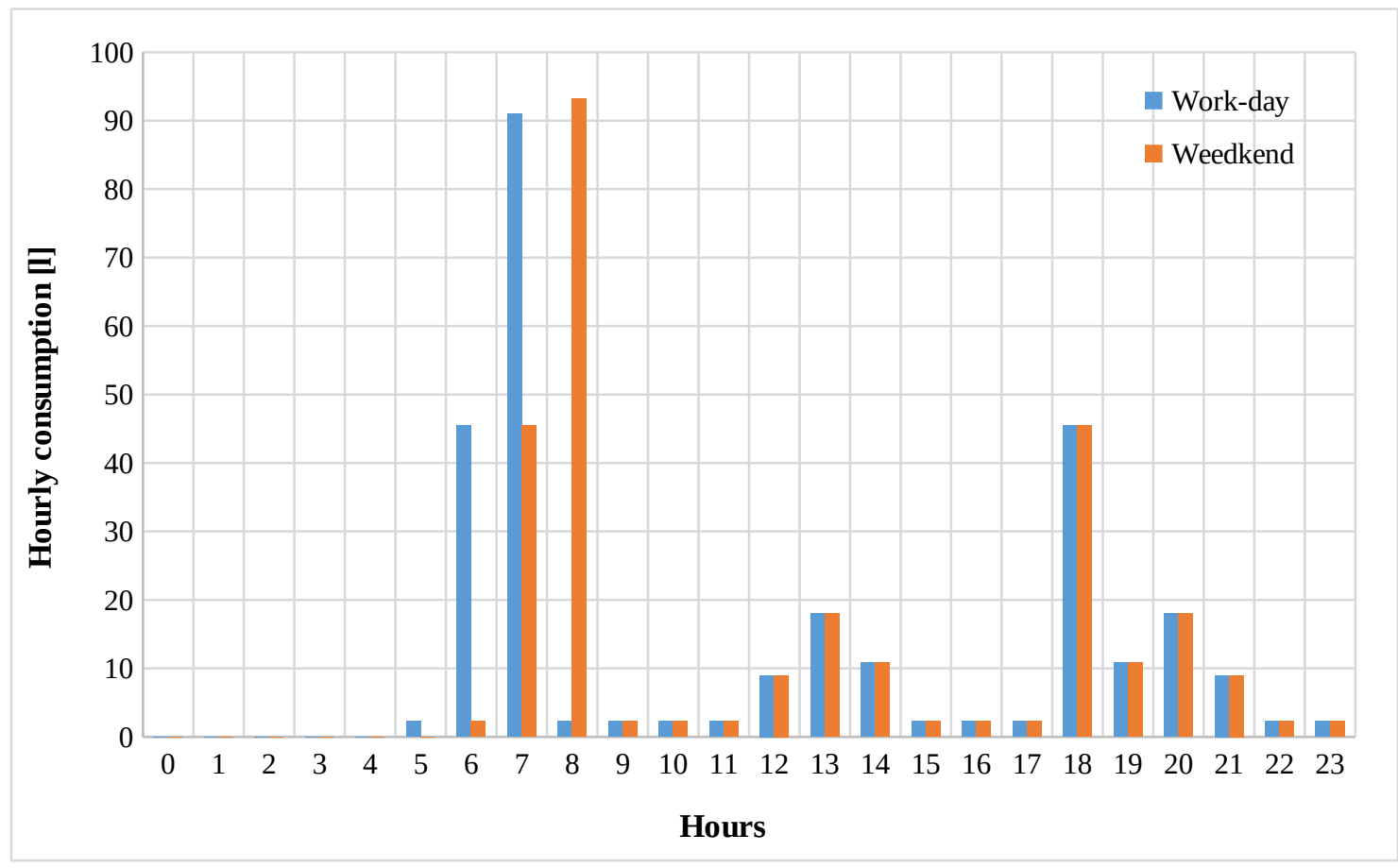

Fig. 11. Work-day and weekend hourly consumption in January.

To determine the hourly trend on weekends and holidays, the authors considered different user habits:

a) $65 \%$ of total load is related to a concentrated DHW need. This consumption is attributable to shower use; the period is from 6.00 AM to 8.00 AM and at 6.00 PM.

b) $20 \%$ of the load is referred to the distributed DHW use represented by periodic cleaning (i.e. hands and teeth). The distribution of these loads takes into account periods of greater load, just before or after main meals:

$30 \%$ is from 12.00 AM to $2.00 \mathrm{PM}$ with $50 \%$ at $1.00 \mathrm{PM} 30 \%$ is from $7.00 \mathrm{PM}$ to $9.00 \mathrm{PM}$ with $50 \%$ at 8:00 PM.40\% is distributed over the remaining hours of the day.

c) $15 \%$ of total load has instead been considered for another type of use (cleaning dishes, washing machine use,....), considering:

- $50 \%$ of this load from 12.00 AM to 2.00 PM, with a peak at 1.00 PM;

- $50 \%$ of this load from 7.00 PM to 9.00 PM with a peak at 8.00 PM.

As previously indicated, $Q_{A u x}$ values are strongly dependent on the $\beta$ angle; at the same time, the optimum $\gamma$ angle is always $0^{\circ}$ (for the South). To determine the best solar configuration a parametric analysis was carried out for each of the city 9 cities the azimuth angle $\gamma=0^{\circ}$ and a tilt angle ranging $0<\beta<90^{\circ}$ with a step of $3^{\circ}$ (for 31 steps) was considered. The 279 simulations were done in the TRNSYS environment, with a time step of $0.25 \mathrm{~h}$, averaging these four values for each hour.

\subsection{The Sicilian $\beta_{\mathrm{BEST}}$ correlation}

In Fig. $12 Q_{A u x}$ values varying tilt angles for each Sicilian provincial capital city are collected. 


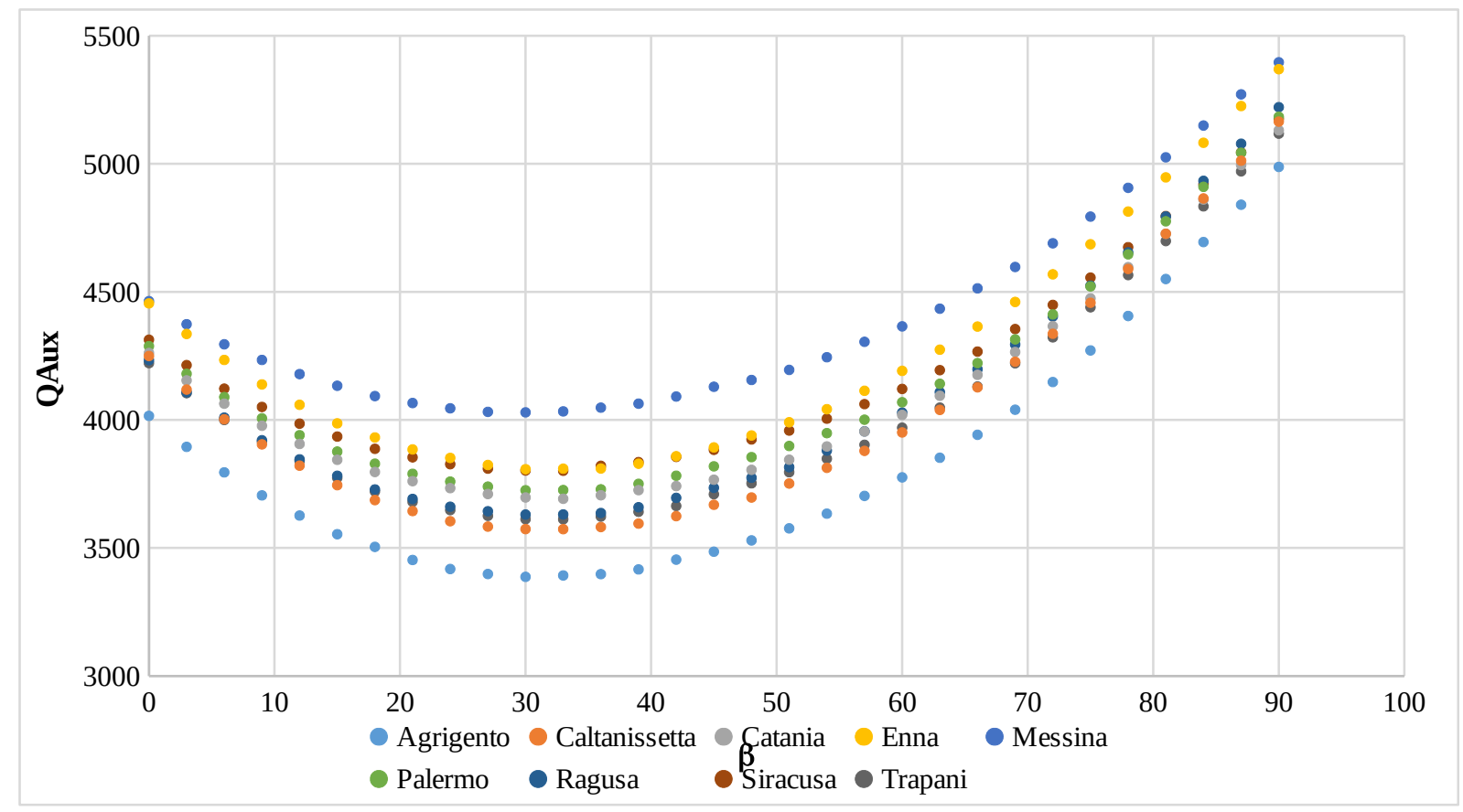

Fig. 12. $\beta_{\text {best }}$ trend versus $Q_{\text {Aux }}$.

In general, a regular trend of the $\beta_{\text {best }}$ angle was observed during the year, permitting the identification of a simple correlation as a function of the month. For example, the optimal monthly values of $\beta$ angle that identify the best configuration for Agrigento city for each month are shown in Fig. 13.

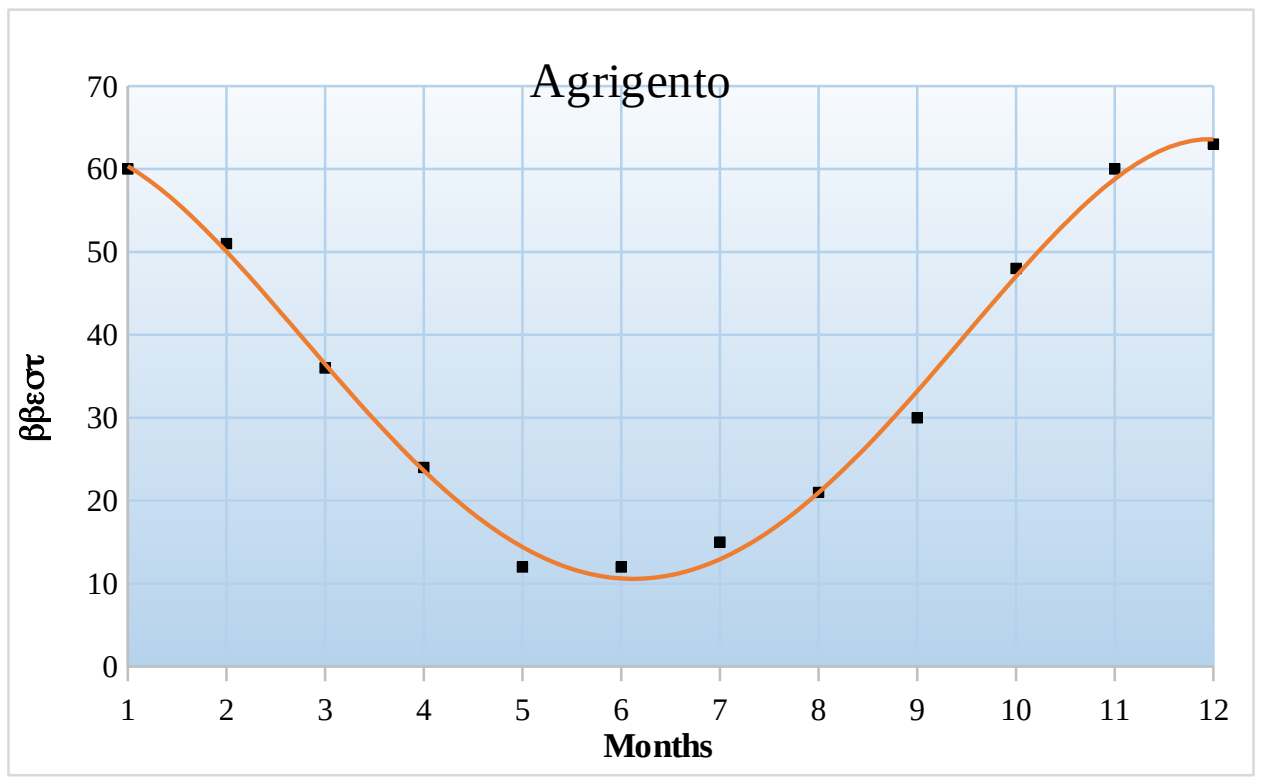

Fig. 13. $\beta_{\text {best }}$ trend for Agrigento city.

The correlation $\beta_{\text {Best }}$ to minimize the $Q_{\text {Aux }}$ and simultaneously maximize S.F. is:

$\beta_{B C z}=-0.0459 m_{i}^{4}+1.1256 m_{i}^{3}-7.2426 m_{i}^{2}+4.2363 m_{i}+62.273$ 
where $m_{i}$ is the $\mathrm{i}^{\text {th }}$ month (from January $=1$ to December $=12$ ); this equation is characterized by high $\mathrm{R}^{2}$ value equal to 0.9938 .

In Table 8 , the $\beta_{\text {best }}$ correlations of each Sicilian city with $\mathrm{R}^{2}$ values are collected.

Table 8

The $\beta_{\text {best }}$ correlation of the nine Sicilian provincial capital cities.

\begin{tabular}{lll}
\hline City & \multicolumn{1}{c}{$\beta_{\text {best }}$ Correlation } & $\mathbf{R}^{2}$ \\
\hline Agrigento & $\beta=-0.0459 m^{4}+1.1256 m^{3}-7.2426 m^{2}+4.2363 m+62.273$ & 0.9938 \\
Caltanissetta & $\beta=-0.0552 m^{4}+1.3340 m^{3}-8.7882 m^{2}+8.4659 m+61.053$ & 0.9859 \\
Catania & $\beta=-0.0547 m^{4}+1.3584 m^{3}-9.3125 m^{2}+11.1410 m+56.992$ & 0.9924 \\
Enna & $\beta=-0.0495 m^{4}+1.2290 m^{3}-8.2793 m^{2}+8.1974 m+59.720$ & 0.9945 \\
Messina & $\beta=-0.0555 m^{4}+1.3593 m^{3}-9.1071 m^{2}+9.5970 m+58.091$ & 0.9956 \\
Palermo & $\beta=-0.0445 m^{4}+1.0863 m^{3}-6.8616 m^{2}+2.5601 m+65.250$ & 0.9924 \\
Ragusa & $\beta=-0.0396 m^{4}+0.9492 m^{3}-5.6449 m^{2}-0.8644 m+65.773$ & 0.9943 \\
Siracusa & $\beta=-0.0599 m^{4}+1.5063 m^{3}-10.646 m^{2}+15.201 m+52.576$ & 0.9939 \\
Trapani & $\beta=-0.0629 m^{4}+1.5668 m^{3}-10.974 m^{2}+15.389 m+54.697$ & 0.9918 \\
\hline
\end{tabular}

For each city the monthly minimum $Q_{A u x}$ values related to the $\beta_{\text {best }}$ angle were evaluated; this value was compared with the $Q_{\text {Aux }}$ evaluated for the yearly best and standard tilt angle. In Table 9, example data for the city of Agrigento are collected: adopting always the best monthly configuration and the yearly $Q_{\text {Aux }}$ value is $3166.47 \mathrm{kWh}$. Adopting the best yearly configuration of $30^{\circ}$ (Best Yearly $\beta$ ) and adopting the standard yearly tilt angle of $37.30^{\circ}$ (Standard Yearly $\beta$ ), the $Q_{A u x}$ values are higher: +220 and $+239 \mathrm{kWh}$ respectively.

\section{Table 9}

The monthly $\beta_{\text {best }}$ and minimum $Q_{A u x}$ values for Agrigento.

\begin{tabular}{|c|c|c|}
\hline \multicolumn{3}{|c|}{ Agrigento } \\
\hline Months & $\mathbf{Q}_{\text {Aux }}$ & $\beta$ \\
\hline & [kWh] & {$\left[{ }^{\circ}\right]$} \\
\hline January & 364.07 & 60 \\
\hline February & 355.30 & 51 \\
\hline March & 357.36 & 36 \\
\hline April & 253.76 & 24 \\
\hline May & 244.71 & 12 \\
\hline June & 187.11 & 12 \\
\hline July & 76.37 & 15 \\
\hline August & 134.66 & 21 \\
\hline September & 196.41 & 30 \\
\hline October & 281.16 & 48 \\
\hline November & 319.37 & 60 \\
\hline December & 396.20 & 63 \\
\hline Yearly $\mathbf{Q}_{\text {Aux }}$ & 3166.47 & - \\
\hline Condition & $\mathbf{Q}_{\text {Aux }}$ & $\beta$ \\
\hline
\end{tabular}




\begin{tabular}{lcc}
\hline & {$[\mathbf{k W h}]$} & {$\left[^{\circ}\right]$} \\
\hline Best Yearly $\boldsymbol{\beta}$ & 3386.85 & 30 \\
Energy saving respect Yearly $\mathbf{Q}_{\text {Aux }}$ & $\mathbf{2 2 0 . 3 8}$ & \\
\hline Standard Yearly $\boldsymbol{\beta}$ & 3405.47 & 37.30 \\
Energy saving respect Yearly $\mathbf{Q}_{\text {Aux }}$ & $\mathbf{2 3 9 . 0 0}$ & \\
\hline
\end{tabular}

The results for all cities are collected in Annex A. Similar observations can be made for seasonal periods; in Table 10, the results of Agrigento city are listed while in Annex $B$ the data of all cities are collected.

\section{Table 10}

The seasonal $\beta_{\text {best }}$ and minimum $Q_{\text {Aux }}$ values for Agrigento.

\begin{tabular}{lcc}
\hline \multicolumn{1}{c}{ Agrigento } & & \\
\hline Months & $\mathbf{Q}_{\text {Aux }}$ & $\boldsymbol{\beta}$ \\
\hline Spring & {$[\mathbf{k W h}]$} & {$\left[{ }^{\circ}\right]$} \\
Summer & 755.49 & 15 \\
Autumn & 423.80 & 21 \\
Winter & 913.69 & 54 \\
\hline Yearly $\mathbf{Q}_{\text {Aux }}$ & 1110.16 & 54 \\
\hline & 3203.13 & - \\
\hline Condition & & \\
\hline Best Yearly $\boldsymbol{\beta}$ & $\mathbf{Q}_{\text {Aux }}$ & $\boldsymbol{\beta}$ \\
Energy saving respect Yearly $\mathbf{Q}_{\text {Aux }}$ & {$[\mathbf{k W h ]}$} & {$\left[{ }^{\circ}\right]$} \\
\hline
\end{tabular}

In all cases, the best yearly $\beta$ configuration determines a higher energy saving in comparison with the yearly standard configuration; of course, energy saving can improve if the user changes the tilt angle each month.

\subsection{The $\beta_{\text {Best }}$ versus Solar Irradiation}

As a knowledge of solar irradiation is fundamental for the optimal design and development of solar energy systems, this parameter is easy to determine since the technical Standard [60] collects the average monthly solar irradiation values for each Italian regional/provincial capital city. Using this knowledge of the irradiation data, it is convenient, in the planning phase, to determine the value of the best $\beta$ angle

The authors developed the following correlations collected in Table 11 , where $\beta_{\text {best }}$ is a function of the monthly average horizontal solar irradiation $\left(H_{h}\right)$ and of the monthly average horizontal solar beam irradiation $\left(H_{b h}\right)$.

Table 11

The monthly $\beta_{\text {best }}$ correlation function of $H_{h}$ and $H_{b h}$.

\begin{tabular}{lcc|cc}
\hline City & $\mathbf{H}_{\mathbf{h}}$ Correlation & $\mathbf{R}^{2}$ & $\mathbf{H}_{\text {bh }}$ Correlation & $\mathbf{R}^{2}$ \\
\hline Agrigento & $\beta=-11.827 H_{h}+91.958$ & 0.977 & $\beta=1.9160 H_{b h}^{2}-22.773 H_{b h}+75.235$ & 0.992
\end{tabular}




\begin{tabular}{lll|ll} 
Caltanissetta & $\beta=-9.7829 H_{h}+85.541$ & 0.931 & $\beta=2.3609 H_{b h}^{2}-22.801 H_{b h}+70.282$ & 0.956 \\
Catania & $\beta=-10.595 H_{h}+85.678$ & 0.956 & $\beta=1.5318 H_{b h}^{2}-19.390 H_{b h}+68.742$ & 0.965 \\
Enna & $\beta=-10.584 H_{h}+86.497$ & 0.956 & $\beta=2.2261 H_{b h}^{2}-22.931 H_{b h}+73.568$ & 0.977 \\
Messina & $\beta=-9.4411 H_{h}+75.712$ & 0.972 & $\beta=2.1660 H_{b h}^{2}-21.302 H_{b h}+64.196$ & 0.984 \\
Palermo & $\beta=-10.736 H_{h}+82.521$ & 0.967 & $\beta=2.3736 H_{b h}^{2}-22.952 H_{b h}+66.975$ & 0.974 \\
Ragusa & $\beta=-10.034 H_{h}+81.652$ & 0.958 & $\beta=1.1807 H_{b h}^{2}-17.107 H_{b h}+66.988$ & 0.967 \\
Siracusa & $\beta=-12.473 H_{h}+95.036$ & 0.981 & $\beta=0.9053 H_{b h}^{2}-19.218 H_{b h}+74.520$ & 0.987 \\
Trapani & $\beta=-10.748 H_{h}+83.696$ & 0.978 & $\beta=1.5614 H_{b h}^{2}-19.118 H_{b h}+64.896$ & 0.978 \\
\hline
\end{tabular}

For each city, the reliability of the correlation is highlighted by the high $\mathrm{R}^{2}$ values, all higher than 0.95; the correlations related to Agrigento city are shown in Fig. 14.
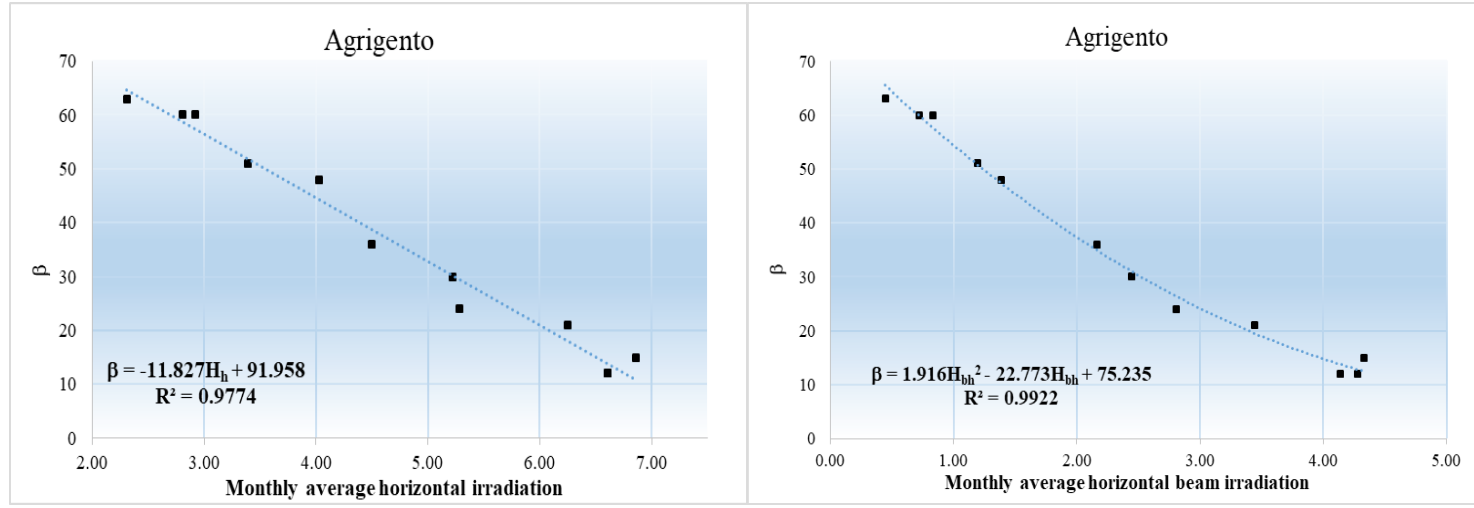

Fig. 14. The monthly $\beta_{\text {best }}$ correlation function of $H_{h}$ and $H_{b h}$ for Agrigento city.

In the same way, the $H_{h}$ and $H_{b h}$ correlations for seasonal uses are collected in Table 12; in this case, the $\beta_{\text {best }}$ is a function of the seasonal average values of solar irradiation.

Table 12

The seasonal $\beta_{\text {best }}$ correlation function of $H_{h}$ and $H_{b h}$.

\begin{tabular}{lcc|lc}
\hline City & \multicolumn{1}{c}{$\mathbf{H}_{\mathbf{h}}$ Correlation } & $\mathbf{R}^{2}$ & $\mathbf{H}_{\mathbf{b h}}$ Correlation & $\mathbf{R}^{2}$ \\
\hline Agrigento & $\beta=-11.181 H_{h}+88.901$ & 0.760 & $\beta=3.5019 H_{b h}^{2}-29.979 H_{b h}+81.61$ & 0.850 \\
Caltanissetta & $\beta=-9.9917 H_{h}+81.508$ & 0.782 & $\beta=2.8063 H_{b h}^{2}-25.005 H_{b h}+71.716$ & 0.846 \\
Catania & $\beta=-11.149 H_{h}+85.987$ & 0.825 & $\beta=3.3258 H_{b h}^{2}-28.827 H_{b h}+75.576$ & 0.897 \\
Enna & $\beta=-10.134 H_{h}+83.153$ & 0.742 & $\beta=4.0989 H_{b h}^{2}-32.065 H_{b h}+80.46$ & 0.843 \\
Messina & $\beta=-8.6317 H_{h}+71.264$ & 0.866 & $\beta=3.2157 H_{b h}^{2}-24.871 H_{b h}+64.529$ & 0.959 \\
Palermo & $\beta=-9.4277 H_{h}+77.603$ & 0.772 & $\beta=3.0318 H_{b h}^{2}-24.262 H_{b h}+67.296$ & 0.850 \\
Ragusa & $\beta=-9.6785 H_{h}+79.766$ & 0.849 & $\beta=1.5301 H_{b h}^{2}-18.466 H_{b h}+67.608$ & 0.879 \\
Siracusa & $\beta=-11.826 H_{h}+92.449$ & 0.840 & $\beta=4.0183 H_{b h}^{2}-34.371 H_{b h}+89.414$ & 0.908 \\
Trapani & $\beta=-9.4490 H_{h}+76.961$ & 0.831 & $\beta=3.1978 H_{b h}^{2}-25.357 H_{b h}+66.732$ & 0.920 \\
\hline
\end{tabular}

In Fig. 15 the $H_{h}$ and $H_{b h}$ correlations for the seasonal uses for Agrigento city are shown. 

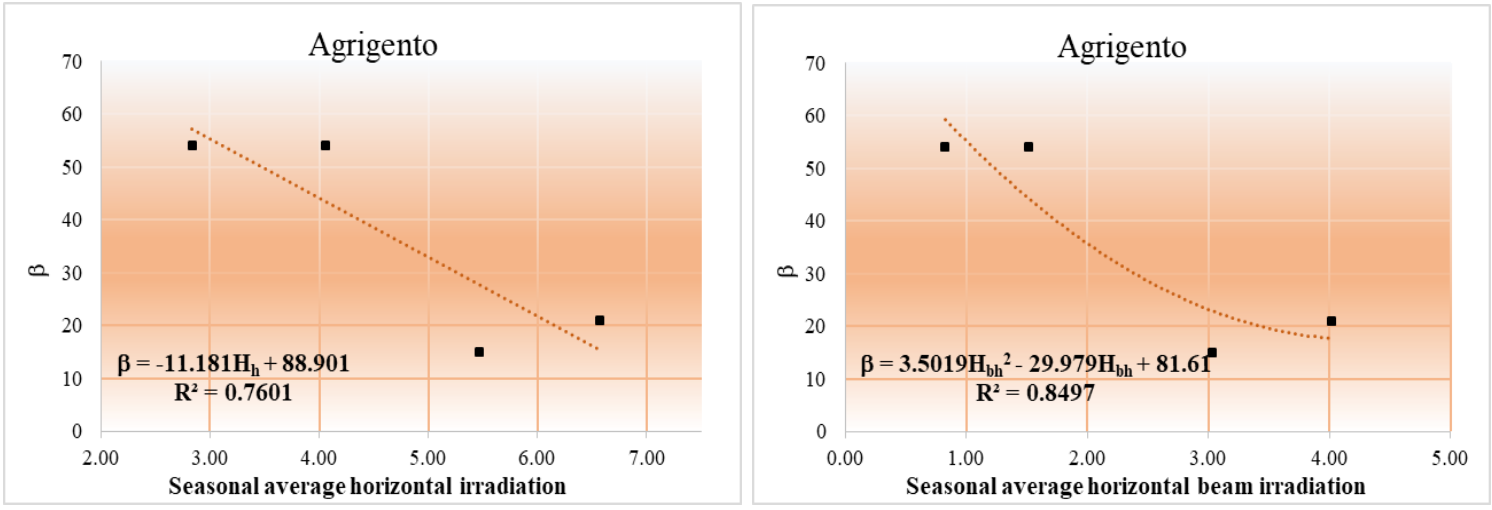

Fig. 15. The seasonal $\beta_{\text {best }}$ correlation function of $H_{h}$ and $H_{b h}$ for Agrigento city.

Collecting all monthly data in the same graph, it was possible to obtain a single correlation valid for the entire region; in Figs. 16 and 17, the trends, the correlations of $\beta_{\text {best }}$ and the $\mathrm{R}^{2}$ values of Sicily region for monthly and seasonal evaluation are indicated.
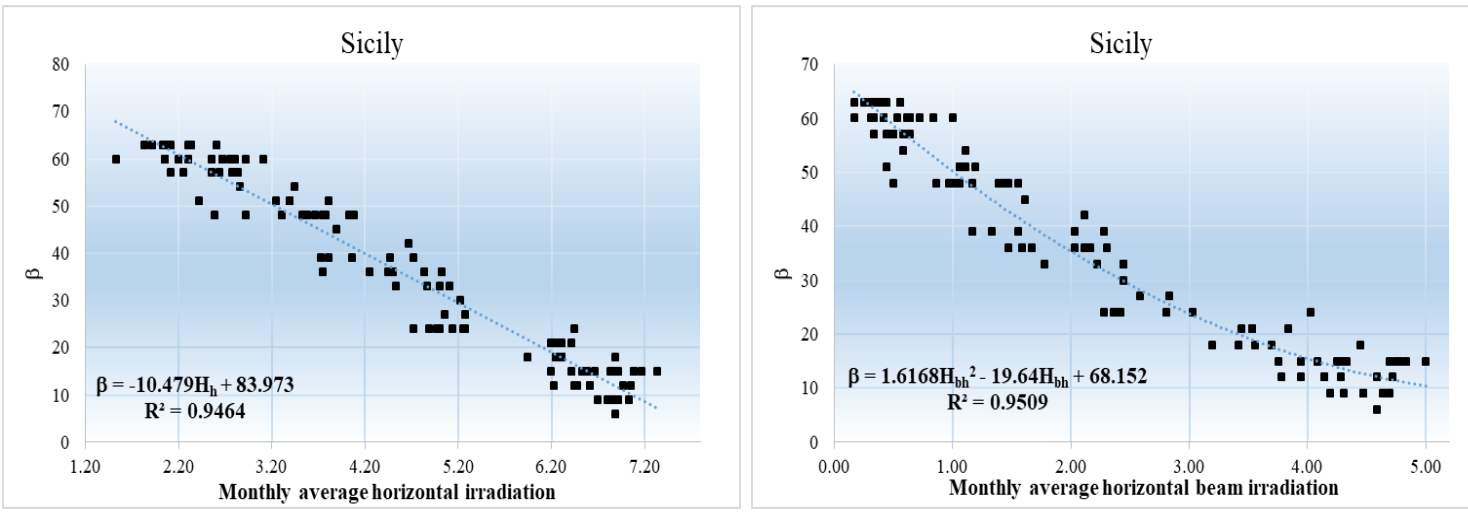

Fig. 16. The monthly $\beta_{\text {best }}$ correlation function of $H_{h}$ and $H_{b h}$ for Sicily.
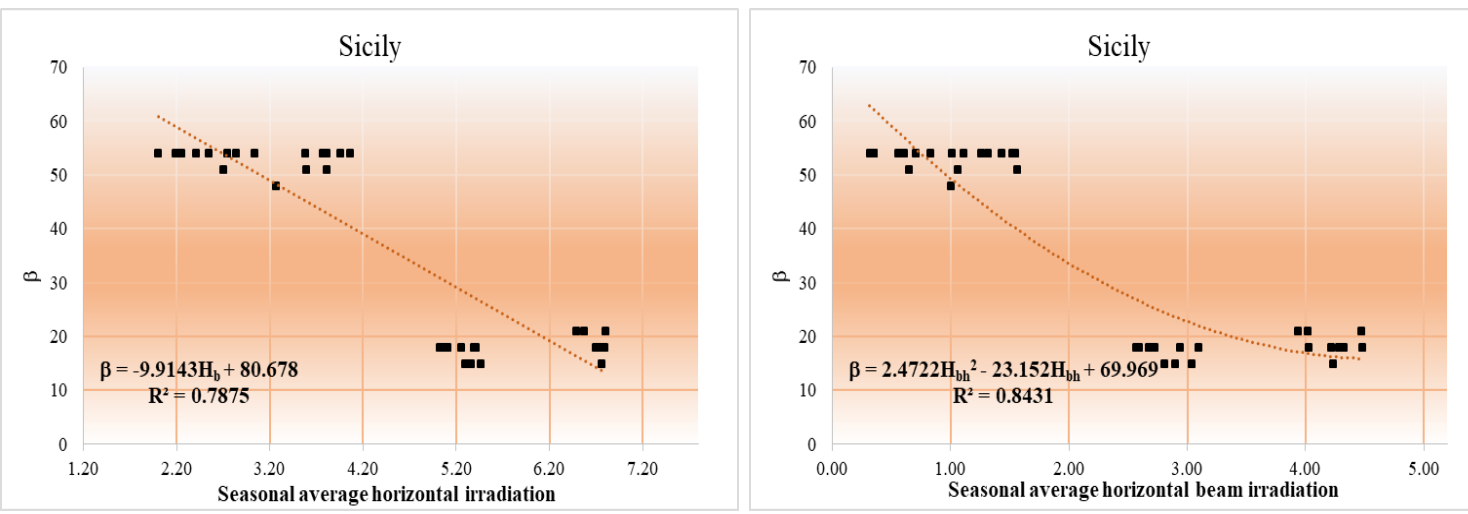

Fig. 17. The seasonal $\beta_{\text {best }}$ correlation function of $H_{h}$ and $H_{b h}$ for Sicily.

Due to the high $\mathrm{R}^{2}$ values, these evaluations could be extended to each Italian region. 


\subsection{The monthly/seasonal $\beta_{\text {best }}$ and the Solar Irradiation}

The results were processed to identify a simple correlation that simultaneously takes into account the solar irradiation which is useful for the whole Sicilian region. In Fig. 18, trends of the $\beta_{\text {best }}$ versus the $H_{b h}$ and the months are shown:
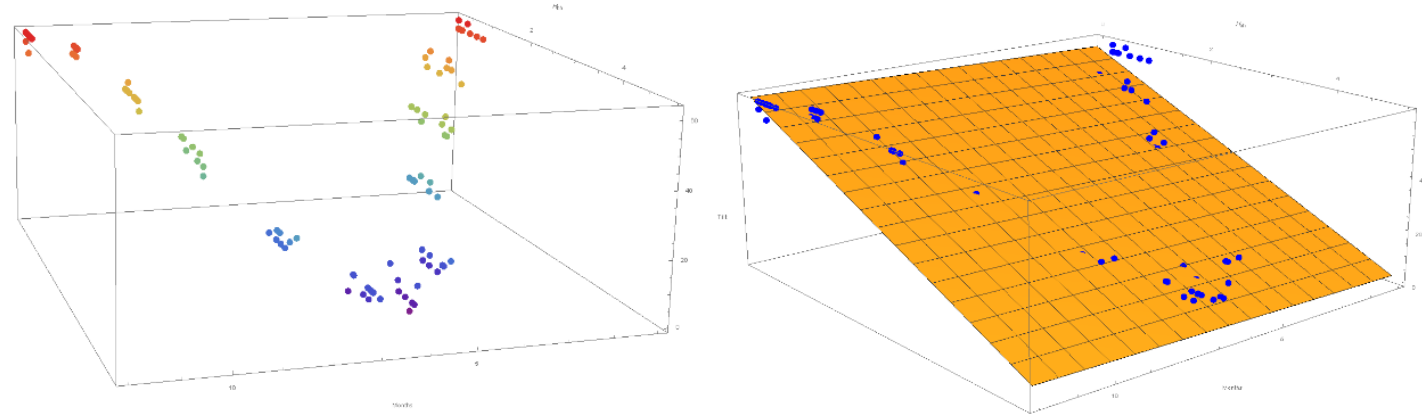

Fig. 18. The $\beta_{\text {best }}$ correlation function of $H_{b h}$ and month for Sicily (Eq.(5)).

The positive trends allow the determination of Eq. (5) characterized by an $\mathrm{R}^{2}=0.9853$

$$
\beta_{\text {best }}=60.542-11.5985 H_{b h}+0.246411 m
$$

In the same way, but with a more complex correlation, the authors propose the following form (Fig. 19):

$\beta_{\text {best }}=59.5976-1.0876 H_{b h}+0.1522 H_{b h}^{2}+8.7244 m-8.5384 m^{2}+1.2724 m^{3}-0.0517 m^{4}$

with an $\mathrm{R}^{2}$ value equal to 0.9976 .

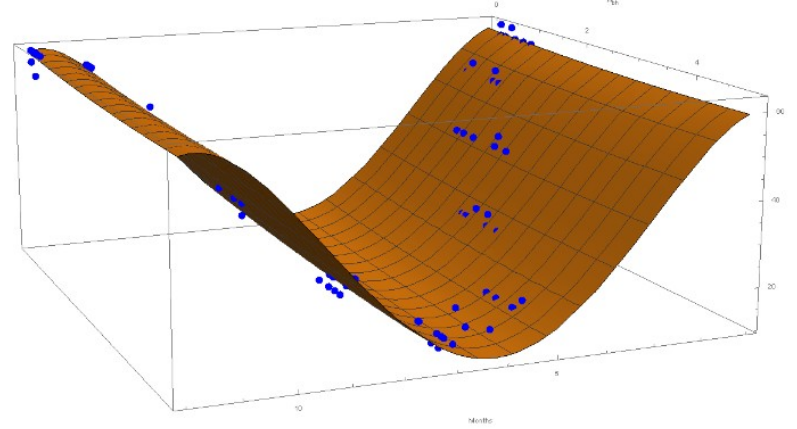

Fig. 19. The $\beta_{\text {best }}$ correlation function of $H_{b h}$ and month for Sicily (Eq. (6)).

Next, the previous results were processed to determine the $\beta_{\text {best }}$ angle as a function of solar irradiance and season, to obtain Eqs. (7) and (8) and these are plotted in Figs. 20 and 21.

$$
\begin{aligned}
& \beta_{\text {best }}=27.9406-6.1464 H_{b h}+8.5186 s \\
& \beta_{\text {best }}=59.7311+2.5547 H_{b h}-0.6201 H_{b h}^{2}-68.2066 s+19.6281 s^{2}+5.0384 s^{3}-1.4493 s^{4}
\end{aligned}
$$


where $s$ represents the season.

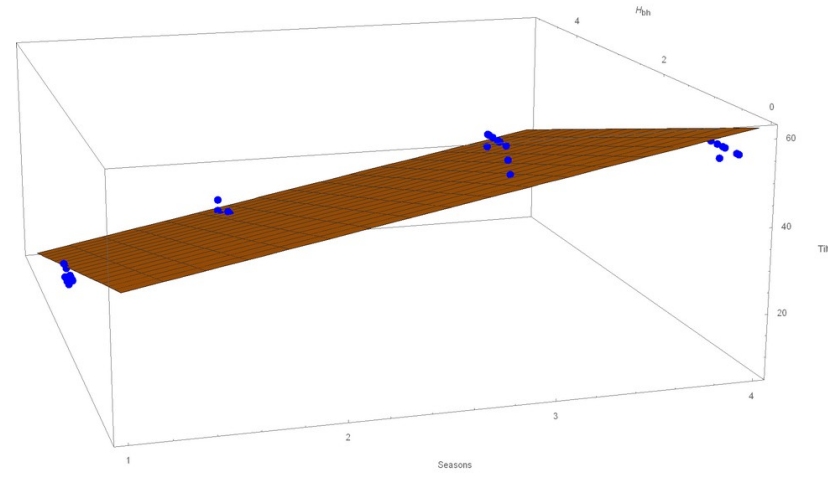

Fig. 20. The $\beta_{\text {best }}$ correlation function of $H_{b h}$ and season for Sicily (Eq. (7))

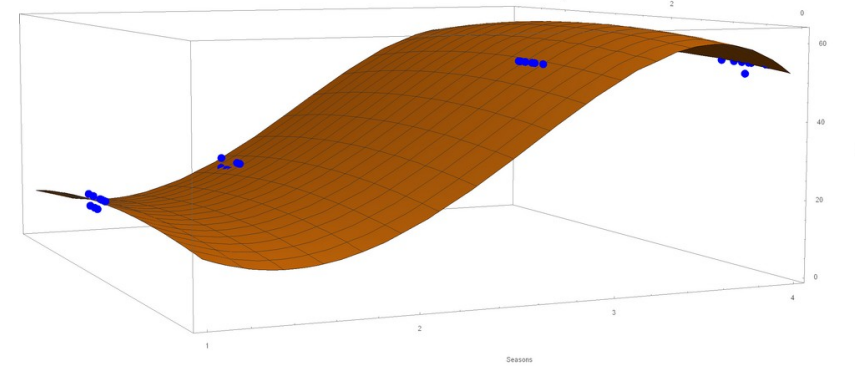

Fig. 21. The $\beta_{\text {best }}$ correlation function of $H_{b h}$ and season for Sicily (Eq.(8))

The reliability of the correlations are guaranteed by the values of $\mathrm{R}^{2}$ equal to 0.9848 and 0.9984 respectively.

\section{CONCLUSION}

This study aimed to determine simple but reliable mathematical correlations that allow the evaluation of the best orientation of the solar collector maximizing its performance for the production of DHW calculating the S.F. and/or $Q_{A u x}$ values without any simulation or software. In this way, any non-expert user can evaluate the best orientation of a solar collector immediately and reliably, knowing only the latitude and the operating period of the solar system.

To demonstrate the validity of the proposed methodology, a detailed case study was described.

A real solar collector and a thermal storage tank characterized by actual parameters and located in the city of Palermo (Southern Italy) was modelled in the TRNSYS environment.

To carry out this analysis, a huge database obtained from a very large number of detailed dynamic simulations was generated. Real average hourly consumption of DHW, variable in the days and seasons, was employed and a parametric analysis was carried out varying tilt, azimuth, and mass flow of the primary fluid. To produce a very detailed and precise time series, the time step of TRNSYS simulations was extremely short; consequently, the changes in the above parameters led to more than 10,000 simulations, which produced a data matrix of more than $5.5 \times 10^{9}$ elements. This extensive collection of data, equal to about $150 \mathrm{~GB}$ of 
output text file, was imported into a MySQL database server to allow better management of the data and a connection with an accurate statistical package. Afterwards, the data output was extracted and processed, generating very reliable correlations that can help to design a solar thermal collector for the production of DHW even when use is fractionated and/or discontinuous.

Based on this idea, the authors also investigated the optimum $\beta$ and $\gamma$ angles of a solar system that maximizes the solar fraction and minimizes the auxiliary power for continuous or occasional use. The availability of simple and immediate feedback boosts the preliminary design stage orienting the designer's choices towards more economic and optimal solutions. To better understand if it is possible to apply the procedure, $i$ the principle steps are indicated as follows:

- choose the location;

- run the parametric simulations;

- import data to MySQL database;

- $\quad$ analyse and find correlations; and

- identify the best configuration to maximize the S.F. and minimize the $Q_{A u x}$ values.

The first phase of the work shows that it is the tilt angle that influences the efficiency of the solar collector. However, considering a real load profile, the optimal tilt angle is not equal to the latitude of the place under consideration, as is often recommended by the operating best practices. The proposed procedure to obtain an optimal tilt angle was replicated for a Sicilian case study. A parametric analysis was carried out for the 9 provincial capital cities of Sicily and for 31 steps of tilt angle $\left(0<\beta<90\right.$ with step of $\left.3^{\circ}\right)$. This data was processed in a MySQL database to obtain some tilt angle correlations that minimize the $Q_{\text {Aux }}$. These correlations are valid for each analysed city and for the entire region of Sicily, and issue a simple function of well-known and available parameters, such as monthly and seasonal solar irradiation.

This paper proposes a methodology that can be replicated, allowing the determination of simple correlations that can make the first evaluation phase during renewable energy planning quicker and with a high degree of reliability. Indeed, this work represents only the first step in a wider research project that will allow more general correlations to be obtained for evaluating the optimal installation conditions in any context, for any requirements and at any latitude.

\section{REFERENCES}

[1] Ghosh HR, Bhowmik NC, Hussain M. Determining seasonal optimum tilt angles, solar radiations on variously oriented, single and double axis tracking surfaces at Dhaka. Renew Energy 2010;35:1292-7. doi:10.1016/j.renene.2009.11.041.

[2] Elminir HK, Ghitas AE, El-Hussainy F, Hamid R, Beheary MM, Abdel-Moneim KM. Optimum solar flat-plate collector slope: Case study for Helwan, Egypt. Energy Convers Manag 2006;47:624-37. doi:10.1016/j.enconman.2005.05.015.

[3] Benghanem M. Optimization of tilt angle for solar panel: Case study for Madinah, Saudi Arabia. Appl Energy 2011;88:1427-33. doi:10.1016/j.apenergy.2010.10.001.

[4] Shariah A, Al-Akhras M-A, Al-Omari IA. Optimizing the tilt angle of solar collectors. Renew Energy 2002;26:587-98. doi:10.1016/S0960-1481(01)00106-9.

[5] Hottel C. Performance of flat plate energy collectors: space heating with solar energy. Course Symp. Cambridge, 1954.

[6] Löf GOG, Tybout RA. Cost of house heating with solar energy. Sol Energy 1973;14:253-78. doi:10.1016/0038-092X(73)90094-7.

[7] Kern J, Harris I. On the optimum tilt of a solar collector. Sol Energy 1975;17:97-102. doi:10.1016/0038-092X(75)90064-X. 
[8] HEYWOOD H. Operating experiences with solar water heating. IHVEJ 1971;39:63-9.

[9] Yellott $\mathrm{H}$. Utilization of sun and sky radiation for heating cooling of buildings. ASHRAE J 1973;15:31.

[10] Lewis G. Optimum tilt of a solar collector. Sol Wind Technol 1987;4:407-10. doi:10.1016/0741-983X(87)90073-7.

[11] Garg, H.P., Gupta CL. FLAT PLATE COLLECTOR - EXPERIMENTAL STUDIES AND DESIGN DATA FOR INDIA. Int. Sol. Energy Soc. Congr., n.d.

[12] El-Kassaby MM. Monthly and daily optimum tilt angle for south facing solar collectors; theoretical model, experimental and empirical correlations. Sol Wind Technol 1988;5:589-96. doi:10.1016/0741-983X(88)90054-9.

[13] Gopinathan KK. Solar radiation on variously oriented sloping surfaces. Sol Energy 1991;47:173-9. doi:10.1016/0038-092X(91)90076-9.

[14] Soulayman SS. On the optimum tilt of solar absorber plates. Renew Energy 1991;1:551-4. doi:10.1016/0960-1481(91)90070-6.

[15] Morcos VH. Optimum tilt angle and orientation for solar collectors in Assiut, Egypt. Renew Energy 1994;4:291-8. doi:10.1016/0960-1481(94)90032-9.

[16] Ibrahim D. Optimum tilt angle for solar collectors used in Cyprus. Renew Energy 1995;6:813-9. doi:10.1016/0960-1481(95)00070-Z.

[17] Yakup MA bin HM, Malik A. Optimum tilt angle and orientation for solar collector in Brunei Darussalam. Renew Energy 2001;24:223-34. doi:10.1016/S09601481(00)00168-3.

[18] Tang R, Wu T. Optimal tilt-angles for solar collectors used in China. Appl Energy 2004;79:239-48. doi:10.1016/j.apenergy.2004.01.003.

[19] Kamali GA, Moradi I, Khalili A. Estimating solar radiation on tilted surfaces with various orientations: a study case in Karaj (Iran). Theor Appl Climatol 2006;84:23541. doi:10.1007/s00704-005-0171-y.

[20] Chandel SS, Aggarwal RK. Estimation of hourly solar radiation on horizontal and inclined surfaces in Western Himalayas. Smart Grid Renew Energy 2011;2:45.

[21] Tiwari GN, Ahmad MJ. Optimization of Tilt Angle for Solar Collector to Receive Maximum Radiation. Open Renew Energy J 2009. doi:10.2174/1876387100902010019.

[22] Ng KM, Adam NM, Inayatullah O, Kadir MZAA. Assessment of solar radiation on diversely oriented surfaces and optimum tilts for solar absorbers in Malaysian tropical latitude. Int J Energy Environ Eng 2014;5:75. doi:10.1007/s40095-014-0075-7.

[23] Jakhrani AQ, Othman A, Rigit ARH, Samo SR, Ahmed S. Estimation of Incident Solar Radiation on Tilted Surface by Different Empirical Models. Int J Sci Res Publ 2012.

[24] Jakhrani AQ, Samo SR, Rigit ARH, Kamboh SA. Selection of models for calculation of incident solar radiation on tilted surfaces. World Appl Sci J 2013. doi:10.5829/idosi.wasj.2013.22.09.316.

[25] Dunlap MA, Marion W, Wilcox S. Solar radiation data manual for flat-plate and concentrating collectors. 1994.

[26] Manes A, Ianetz A. On the optimum exposure of flat-plate fixed solar collectors. Sol Energy 1983;31:21-7. doi:10.1016/0038-092X(83)90030-0.

[27] Handoyo EA, Ichsani D, Prabowo. The Optimal Tilt Angle of a Solar Collector. Energy Procedia 2013;32:166-75. doi:10.1016/j.egypro.2013.05.022.

[28] Bilbao J, De Miguel A, Ayuso A, Franco J. Iso-radiation maps for tilted surfaces in the Castile and Leon region, Spain. Energy Convers Manag 2003;44:1575-88. doi:10.1016/S0196-8904(02)00161-9.

[29] Beringer S, Schilke H, Lohse I, Seckmeyer G. Case study showing that the tilt angle of photovoltaic plants is nearly irrelevant. Sol Energy 2011;85:470-6. 
doi:10.1016/j.solener.2010.12.014.

[30] Asl-Soleimani E, Farhangi S, Zabihi M. The effect of tilt angle, air pollution on performance of photovoltaic systems in Tehran. Renew Energy 2001;24:459-68. doi:10.1016/S0960-1481(01)00029-5.

[31] Bekker B. Irradiation and PV array energy output, cost, and optimal positioning estimation for South Africa. J Energy South Africa 2007.

[32] Hafez AZ, Soliman A, El-Metwally KA, Ismail IM. Tilt and azimuth angles in solar energy applications - A review. Renew Sustain Energy Rev 2017;77:147-68. doi:10.1016/j.rser.2017.03.131.

[33] Hartner M, Ortner A, Hiesl A, Haas R. East to west - The optimal tilt angle and orientation of photovoltaic panels from an electricity system perspective. Appl Energy 2015;160:94-107. doi:10.1016/j.apenergy.2015.08.097.

[34] Jeyaprabha SB, Selvakumar AI. Optimal sizing of photovoltaic/battery/diesel based hybrid system and optimal tilting of solar array using the artificial intelligence for remote houses in India. Energy Build 2015;96:40-52. doi:10.1016/j.enbuild.2015.03.012.

[35] Tanaka H. Theoretical analysis of a vertical multiple-effect diffusion solar still coupled with a tilted wick still. Desalination 2016;377:65-72. doi:10.1016/j.desal.2015.09.013.

[36] Pan N, Wang S, Shen C. A fundamental study on characteristic of thermoacoustic engine with different tilt angles. Int $J$ Heat Mass Transf 2014;74:228-37. doi:10.1016/j.ijheatmasstransfer.2014.03.019.

[37] Sun L, Lu L, Yang H. Optimum design of shading-type building-integrated photovoltaic claddings with different surface azimuth angles. Appl Energy 2012;90:233-40. doi:10.1016/j.apenergy.2011.01.062.

[38] Santos ÍP Dos, Rüther R. The potential of building-integrated (BIPV) and buildingapplied photovoltaics (BAPV) in single-family, urban residences at low latitudes in Brazil. Energy Build 2012;50:290-7. doi:10.1016/j.enbuild.2012.03.052.

[39] Corrada P, Bell J, Guan L, Motta N. Optimizing solar collector tilt angle to improve energy harvesting in a solar cooling system. Energy Procedia, vol. 48, Elsevier Ltd; 2014, p. 806-12. doi:10.1016/j.egypro.2014.02.093.

[40] Gitan AA, Abdulmalek SH, Dihrab SS. Tracking collector consideration of tilted collector solar updraft tower power plant under Malaysia climate conditions. Energy 2015;93:1467-77. doi:10.1016/j.energy.2015.09.009.

[41] Skeiker K. Optimum tilt angle and orientation for solar collectors in Syria. Energy Convers Manag 2009;50:2439-48. doi:10.1016/j.enconman.2009.05.031.

[42] Patkó I, Szeder A, Patkó C. Evaluation the impact tilt angle on the sun collectors. Energy Procedia, vol. 32, Elsevier Ltd; 2013, p. 222-31. doi:10.1016/j.egypro.2013.05.029.

[43] Jafarkazemi F, Ali Saadabadi S, Pasdarshahri H. The optimum tilt angle for flat-plate solar collectors in Iran. J. Renew. Sustain. Energy, vol. 4, 2012. doi:10.1063/1.3688024.

[44] Moghadam H, Tabrizi FF, Sharak AZ. Optimization of solar flat collector inclination. Desalination 2011;265:107-11. doi:10.1016/j.desal.2010.07.039.

[45] Srivastava R, Tiwari AN, Giri VK. An overview on performance of PV plants commissioned at different places in the world. Energy Sustain Dev 2020;54:51-9. doi:10.1016/j.esd.2019.10.004.

[46] Milosavljević DD, Pavlović TM, Piršl DS. Performance analysis of A grid-connected solar PV plant in Niš, republic of Serbia. Renew Sustain Energy Rev 2015;44:423-35. doi:10.1016/j.rser.2014.12.031.

[47] Emziane M, Buildings MAA-E and, 2015 undefined. Performance assessment of 
rooftop PV systems in Abu Dhabi. Elsevier n.d.

[48] Ayompe LM, Duffy A, McCormack SJ, Conlon M. Measured performance of a 1.72 $\mathrm{kW}$ rooftop grid connected photovoltaic system in Ireland. Energy Convers Manag 2011;52:816-25. doi:10.1016/j.enconman.2010.08.007.

[49] Klein SA, others. TRNSYS-A Transient System Simulation Tool, Ver 14.2. Sol Energy Lab Univ Wisconsin, MadLson, WI 1996.

[50] Ahmed K, Pylsy P, Kurnitski J. Hourly consumption profiles of domestic hot water for different occupant groups in dwellings. Sol Energy 2016;137:516-30. doi:10.1016/j.solener.2016.08.033.

[51] Blokker EJM, Vreeburg JHG, van Dijk JC. Simulating Residential Water Demand with a Stochastic End-Use Model. J Water Resour Plan Manag 2010;136:19-26. doi:10.1061/(ASCE)WR.1943-5452.0000002.

[52] Good N, Zhang L, Navarro-Espinosa A, Mancarella P. High resolution modelling of multi-energy domestic demand profiles. Appl Energy 2015;137:193-210. doi:10.1016/j.apenergy.2014.10.028.

[53] Parker DS. Research highlights from a large scale residential monitoring study in a hot climate. Energy Build 2003;35:863-76. doi:10.1016/S0378-7788(02)00244-X.

[54] Stokes M, Rylatt M, Lomas K. A simple model of domestic lighting demand. Energy Build 2004;36:103-16. doi:10.1016/j.enbuild.2003.10.007.

[55] Caldera M, Puglisi G, Zanghirella F, Ungaro P, Cammarata G. Numerical modelling of the thermal energy demand in Italian households through statistical data. Int J Heat Technol 2018;36:381-90. doi:10.18280/ijht.360201.

[56] Vinogradov AN, Chipulis VP. Influence of Indirect Measurements on the Account of General Needs of Hot Water Consumption. 2018 Int. Multi-Conference Ind. Eng. Mod. Technol., IEEE; 2018, p. 1-4. doi:10.1109/FarEastCon.2018.8602937.

[57] SRCC. Solar Collector technical sheet n.d.

[58] Solar Hot Water \&amp; Heating Manufacturer | Solar Hot Water \&amp; Heating Manufacturer n.d.

[59] Kalogirou SA. Solar Energy Engineering: Processes and Systems. 2009. doi:10.1016/B978-0-12-374501-9.00014-5.

[60] Ente Nazionale Italiano di Normazione. UNI 10349:2016 "Riscaldamento e raffrescamento degli edifici - Dati climatici. Ente Naz Ital Di Normaz 2016. 